\title{
Can Public Rankings Improve School Performance?
}

\section{Evidence from a Nationwide Reform in Tanzania *}

\author{
Jacobus Cilliers $^{\dagger} \quad$ Isaac M. Mbiti ${ }^{\ddagger} \quad$ Andrew Zeitlin ${ }^{\S}$
}

March 18, 2020

\begin{abstract}
In 2013, Tanzania introduced "Big Results Now in Education", a low-stakes accountability program that published both nationwide and within-district school rankings. Using data from the universe of school performance from 2011-2016, we identify the impacts of the reform using a difference-in-differences estimator that exploits the differential pressure exerted on schools at the bottom of their respective district rankings. We find that BRN improved learning outcomes for schools in the bottom two deciles of their districts. However, the program also led schools to strategically exclude students from the terminal year of primary school.
\end{abstract}

JEL Classification: I21, I25, I28, O15

\footnotetext{
* This research was funded by the Research on Improving Systems of Education (RISE) initiative of the UK DFID and Australian Aid, and administered by Oxford Policy Management. Fozia Aman, Ben Dandi, Austin Dempewolff, and Anna Konstantinova provided exceptional research support. We are grateful to Shardul Oza, Wale Wane, Joseph Mmbando, Youdi Schipper and Twaweza for their support and assistance in helping us assemble datasets used in the study. For helpful comments and suggestions we thank Nora Gordon, James Habyarimana, Billy Jack, Kitila Mkumbo, Lant Pritchett, Justin Sandefur, Richard Shukia, Abhijeet Singh, Jay Shimshack, Miguel Urqiola and seminar participants at the RISE conference, Twaweza conference in Dar es Salaam, DC Policy Day, Georgetown University, and University of Virginia. The authors do not have any conflicts of interest to disclose. The online appendix for this paper is available at http://jhr. uwpress.org/. Data and programs for replication materials are available through the Dataverse at https://doi.org/10.7910/DVN/ABVMCL. Our replications files do not include the World Bank SDI data which are available at https://www.sdindicators.org/. The restricted access version of the SDI data can be obtained by contacting the SDI team at sdi@worldbank.org with a statement of research objectives and a justification.

${ }^{\dagger}$ Georgetown University; ejc93@georgetown.edu

${ }^{\ddagger}$ University of Virginia, J-PAL, BREAD, NBER, IZA; imbiti@virginia.edu

$\S$ Georgetown University and Center for Global Development; az332@georgetown.edu
} 


\section{Introduction}

School performance rankings based on standardized tests are typically used as the foundation of accountability systems. Such systems are thought to be more effective if school performance is used to sanction or reward schools (Hanushek and Raymond, 2005). However, there are concerns that such "high-stakes" systems can encourage unintended behaviors, including gaming, teaching to the test, and neglecting unrewarded tasks or academic subjects (Baker, 2002, 1992; Holmstrom and Milgrom, 1991). Further, political constraints, such as opposition from teachers, make these systems difficult to implement. As a result, the first accountability systems that are implemented tend to be "low-stakes" systems that simply focus on publicizing information about school performance. ${ }^{1}$ Although successful low-stakes accountability reforms have taken place in contexts when parents are willing and able to act on the information provided to them (Andrabi et al., 2017; Camargo et al., 2018; Koning and van der Wiel, 2012), these systems may also be effective if they create sufficient reputational pressure for higher-level education administrators or school staff (Bruns et al., 2011; Figlio and Loeb, 2011). But such pressure could be a double-edged sword, encouraging the same distortions and perverse behaviors that are associated with high-stakes systems.

In this paper, we study the intended and unintended consequences of a nationwide accountability system implemented in Tanzania in 2012. In response to growing concerns about school quality, the Government of Tanzania instituted a package of reforms that were branded "Big Results Now in Education" (BRN) (World Bank, 2018b). The BRN education program was a flagship reform that was overseen and coordinated by the Office of the President and implemented by the Ministry of Education. It aimed to improve the quality of education in Tanzania through a series of top-down accountability measures that leveraged the political prominence of the reforms to pressure bureaucrats in the education system.

A key BRN policy was its school ranking initiative, under which the central government disseminated information about individual primary schools' average scores in the Primary School Leaving Exam (PSLE), and their corresponding national and within-district rankings. As this was the most prominent and comprehensively implemented BRN component (Todd and Attfield, 2017), we focus our study on examining the impacts of this intervention. We interpret the BRN reforms as a low-stakes accountability reform since there were no financial consequences for low school performance on the PSLE. ${ }^{2}$ Prior to the reform, the government only released information about students who passed the PSLE. With the reform, the complete set of PSLE results, including school rankings, was released on a website and shared directly with schools through District

\footnotetext{
${ }^{1}$ This pattern is clearly seen in many US states, as well as in the UK, where the first step towards an accountability system was a school report card initiative (Burgess et al., 2005). Low-stakes accountability reforms built around reputational incentives for schools have also been implemented in Brazil, Chile, Colombia, Mexico, and Pakistan (Figlio and Loeb, 2011).

${ }^{2}$ We test this assertion in our data and confirm that low performing schools saw no reductions in school resources. See Section 5 for more details. This contrasts with studies in other contexts such as Craig et al. (2013, 2015), who show that school funding was closely tied to school performance.
} 
Education Officers (DEOs), who supervise public schools within their jurisdictions and have considerable discretion over human and physical resource decisions therein. As there were limited efforts to disseminate this information to parents - and survey data collected under our study confirm that parental awareness of these rankings was minimal - the reforms leveraged bureaucratic incentives of DEOs, head-teachers, and other education officials through top-down pressure.

To study BRN's impacts, we assemble a novel dataset that combines administrative and (matched) sample-based data from several sources to estimate the impact of the BRN reforms on a comprehensive set of school-level outcomes. For our main analysis, we construct a panel of administrative data on exam outcomes, covering all Tanzanian primary schools in the period from 2011 to 2016. To shed light on the potential mechanisms through which the reforms affect test scores, we match our administrative data on examinations to data on student enrollments in 2015 and 2016 from the government's Education Management Information System (EMIS), as well as to micro-data from the World Bank's Service Delivery Indicators, a nationally representative panel of almost 400 schools in Tanzania, which were collected in 2014 and 2016.

We identify the effects of the BRN's publication of within-district school ranks using a differences-indifferences strategy that exploits the differential pressure faced by schools across the ranking distribution under BRN. In a given year, a school will be ranked using the prior year's PSLE test score. We posit that the publication of school rankings would exert more pressure on schools that fall near the bottom of the distribution in their district, where (relative) failure is more salient compared to schools in the middle of the distribution. In this respect, our study is similar to prior work that has used the differential pressures generated by accountability reforms to study their consequences for schools and teachers (Chiang, 2009; Dee and Wyckoff, 2015; Figlio and Rouse, 2006; Reback et al., 2014; Rockoff and Turner, 2010; Rouse et al., 2013). ${ }^{3}$ We operationalize this hypothesis of differential pressure in a parsimonious manner by comparing how schools respond to being ranked in the bottom two deciles relative to the middle six deciles (our reference category) in the pre-BRN (2012) versus post-BRN (2013-2016) periods.

As the pre-reform relationship between schools rankings and subsequent school performance may be driven in part by mean-reversion (Chay et al., 2005; Kane and Staiger, 2002), our difference-in-differences strategy will use pre- and post-reform data to identify the effect of the BRN school ranking program by netting out pre-reform estimates of mean-reversion and other stable processes through which rankings affect school performance.

As better-ranked schools have better test scores, it can be difficult to disentangle the effects of the district

\footnotetext{
${ }^{3}$ To the extent that schools elsewhere in the ranking distribution are unaffected by the reform, such a strategy provides not only a test of the existence of a BRN effect, but an estimate of its total impact. This contrasts with settings where 'sharp' discontinuities identify local impacts of particular mechanisms within a given policy environment, as in Mizala and Urquiola (2013); Rockoff and Turner (2010); and others.
} 
rankings from other effects driven by (or associated with) levels of PSLE test scores. To circumvent this potential confounding effect, we exploit between-district heterogeneity where many schools have the same average test scores, but radically different within-district rankings in both pre- and post-BRN periods. ${ }^{4}$ This allows us to compare the response of schools of similar quality (measured by test scores) but that are exposed to different within-district rankings. Flexible, year-specific controls for absolute test scores absorb mean-reversion or other processes that govern the evolution of absolute test scores in each year through mechanisms other than district ranks. Moreover, the construction of school-level panel data allows fixed effect estimates to address potential time-invariant confounds.

We find that the BRN school rankings intervention increased average PSLE test scores by approximately 20 percent of a pre-reform school standard deviation for schools in the bottom decile, relative to schools ranked in the middle six deciles. The pass rate for these schools improved by 5.7 percentage points (or 36 percent relative to the pre-BRN pass rate among bottom decile schools), and on average two additional students from each of these schools passed the PSLE - a 24 percent increase relative to the pre-BRN number of passing students for bottom decile schools. Our estimated effect sizes for the bottom decile schools are similar to the experimental estimate of distributing school report cards in Pakistan (Andrabi et al., 2017). Our estimates are also within the range typically found in evaluations of teacher performance pay programs and accountability schemes (Figlio and Loeb, 2011; Muralidharan and Sundararaman, 2011).

We explore several potential mechanisms through which the BRN reform led to these test score gains by matching administrative data on test scores with the World Bank's Service Delivery Indicator school-level panel dataset. Despite the ability of District Education Officers (and other government officials) to redirect resources to bottom-ranked schools, we do not find any evidence that these schools received additional teachers, textbooks, financial grants, or inspections. In addition, we do not find any evidence of increased effort (measured by school absenteeism or time teaching) among these schools. However, we find that were two fewer students taking the PSLE in bottom ranked schools. This is roughly a four percent reduction, given pre-reform average class-size of 48 pupils among these schools. Examining administrative enrollment data, we find similar reductions in seventh-grade enrollment in the bottom-ranked schools, suggesting students are induced to leave seventh grade altogether. We do not find statistically significant changes in enrollment in other grades, as would be implied by induced grade repetition. Further, we do not find any evidence that these seventh-grade enrollment reductions reflect students moving from bottom-ranked schools to betterranked schools. Robustness checks support the interpretation that these school responses - both the positive learning gains and the negative enrollment effects - appear to be driven by the district rankings and not by

\footnotetext{
${ }^{4}$ For example, a school with the 2011 national average PSLE mark of 111 could find itself anywhere from the bottom 5 percent to the top 5 percent of its district, depending on the district in which it resided. Reback et al. (2014) exploit similar heterogeneity in their evaluation of the No Child Left Behind reform.
} 
other, contemporaneous reform components.

Our study contributes to the literature of education system accountability in three distinct ways. First, we show that despite the low-stakes nature of the school ranking initiative and the limited potential parental response to the school rankings, schools did respond to the reform. Given parents' minimal awareness of the rankings and limited scope for school choice, this suggests that top-down pressure and bureaucratic reputational incentives are capable of driving learning improvements. This is a novel finding, given that the existing literature on school ranking interventions has only showed these to be effective when there is sufficient school choice or high-stakes consequences (Andrabi et al., 2017; Figlio and Loeb, 2011; Hastings and Weinstein, 2008; Koning and Van der Wiel, 2013; Nunes et al., 2015).

Second, we show that that even low-stakes accountability systems can induce perverse behavioral responses. Previous studies have shown that schools responded to accountability systems by focusing on students near the proficiency margin (Neal and Schanzenbach, 2010), excluding lower-performing students from testing by suspending them or categorizing them as disabled (Figlio, 2006; Figlio and Getzler, 2002), or manipulating exam results outright (Jacob, 2005). However, these behaviors are typically associated with high-stakes accountability systems which impose significant consequences on under-performing schools. Despite the limited consequences of their performance, bottom-ranked schools in Tanzania responded by excluding students from the assessment.

Third, we add to the limited evidence base on the effectiveness of nationwide accountability reforms in developing contexts. Our study documents the introduction of such an accountability system and provides evidence of its short-run impacts. The existing evidence on accountability reforms focuses on developed countries, and on the U.S. No Child Left Behind Act of 2002 in particular, where findings generally suggest positive test score impacts (see Figlio and Loeb, 2011, for an overview). Evidence of accountability reforms in developing countries is more scarce, and is dominated by evaluations of pilot programs of teacher performance pay systems (Glewwe et al., 2010; Muralidharan and Sundararaman, 2011) or bottom-up accountability mechanisms (Banerjee et al., 2010; Lieberman et al., 2014). A potential drawback of these pilot studies is that the nature of their implementation - and, consequently, the incentives they create - may be very different when implemented by government at scale, and, more broadly, the estimates they deliver may fail to capture general equilibrium effects (Bold et al., 2018; Muralidharan and Niehaus, 2017). Unfortunately, larger-scale reforms have often not been evaluated due to lack of a suitable control group (Bruns et al., 2011). ${ }^{5}$ Our paper fills an important gap in this literature by documenting the promise and perils of a

\footnotetext{
${ }^{5}$ An important exception is the case of Chile, where, in the context of a voucher system (Hsieh and Urquiola, 2006), Mizala and Urquiola (2013) use a regression discontinuity design to estimate the effect of receiving a good ranking on schools near the cutoff. However, their study focuses on market outcomes such as enrollment and tuition. They do not examine test scores, and their study focuses on parental choice as a driving mechanism.
} 
low-stakes bureaucratic accountability system, at scale, in a developing country.

\section{Context and reform}

Following the introduction of free primary education, net enrollment rates in Tanzania steadily increased from 59 percent in 2000 to 80 percent in 2010 (Joshi and Gaddis, 2015; Valente, 2015). However, the surging enrollment raised concerns about the quality of education. The basis for this perceived learning crisis is readily seen in results of the Primary School Leaving Exam (PSLE), which is taken at the end of Grade 7 and serves to certify completion of primary education and to determine progression to secondary school. ${ }^{6}$ PSLE pass rates declined from about 70 percent in 2006 to an all-time low of 31 percent in 2012 (Joshi and Gaddis, 2015; Todd and Attfield, 2017). At the same time, independent learning assessments highlighted that only about one in four children in the third grade could read at a second-grade level (Jones et al., 2014; Twaweza, 2012).

In response to these challenges facing the education sector, the Government of Tanzania launched a large-scale, multipronged education reform called Big Results Now in Education (BRN) in 2013, which aimed to raise pass rates on the PSLE to 80 percent by the year $2015 .{ }^{7}$ The BRN reforms emphasized exam performance and created pressure to demonstrate improvements across the education system. Government ministries were instructed to align their budgets to the reforms, which were coordinated through the Presidential Delivery Bureau, a specialized division of the Office of the President. In a public ceremony, the Education Minister and the Minister for Local Government both pledged that their ministries would endeavor to meet the BRN targets. In addition, national, regional, and district officials signed performance contracts to signal their commitment to the reforms (Todd and Attfield, 2017). District officials who oversaw implementation were required to submit regular progress reports to higher level officials, as well as the Delivery Bureau. The Bureau would then provide feedback and recommendations on the reports. Overall, this structure ensured that there was sufficient political pressure on government bureaucrats to implement the reforms.

The BRN education reforms were comprised of nine separate initiatives that ranged in approach from school management-focused interventions to initiatives aimed at improving the accountability environment such as the school ranking program. In spite of their systemic national ambitions, as we document in Table B.1 in the online Appendix, most of these initiatives were either implemented on a limited scale (as with the remedial education program), rolled out slowly (as with the capitation grant reform), or designed in such

\footnotetext{
${ }^{6}$ The PSLE tests students in Mathematics, Science, English, Kiswahili, and Social Studies. The maximum score on each subject is 50, and individual subject scores are then totaled for each student, up to a maximum of 250 points. A score of 100 or above constitutes a passing score. For more details see https://www.necta.go.tz/psle.

${ }^{7} \mathrm{BRN}$ was introduced as part of larger set of reforms modeled on Malaysias Big Fast Results program.
} 
a way that they did not create effective incentives for schools (as with the incentives for year-on-year test score gains). ${ }^{8}$ Other initiatives focused on early grade learning and were thus not relevant for our study. We therefore focus on the component that was not only implemented universally and immediately, but also central to BRN's emphasis on learning outcomes - the school ranking initiative.

BRN's school ranking initiative disseminated information about each school's average score on the PSLE relative to all other schools in the country (the national ranking), as well as rankings relative to schools in the district (the district ranking). Prior to BRN, District Education officers and schools were only provided with the list of students who passed the PSLE. For the first time, the reform distributed the complete set of results for all students, and included school rankings and average scores. This information was posted on the internet and published in print media and distributed to DEOs. Nearly all DEOs disseminated exam results and district rankings to the 90-110 primary schools within their district (Todd and Attfield, 2017). Surveys we conducted with DEOs in 38 districts show that in 2016 over 90 percent of DEOs who had received the ranking information by the time of our survey held meetings with headteachers to inform them of their rankings and to discuss ways of improving their performance.

Phone surveys conducted with a nationally representative sample of 435 head teachers and 290 School Management Committee chairs in 45 districts in 2016 reveal that head teachers were better informed about their school's within-district rank compared to their national rank. ${ }^{9}$ Almost 75 percent of surveyed head teachers were able to provide an estimate of their school's district rank, but fewer than 20 percent of head teachers could provide an estimate of their national rank. For this reason, and based on evidence we present in Section 6, we focus on estimation of the impacts of BRN's district rankings in particular.

By contrast with head teachers and DEOs, parents were not well informed about the school's rankings. Only 2 percent of surveyed School Management Committee chairs-who are plausibly the most informed parents in the school - were able to provide an estimate about their school's national rank; 22 percent of committee chairs could provide an estimate of their school's district rank. A recent qualitative study reached a similar conclusion, finding that parental understanding of the BRN school ranking initiative was much lower compared to head teachers, DEOs, and teachers (Integrity Research, 2016). This is not surprising, since there was no national dissemination strategy to parents, and the district-level dissemination was targeted at head teachers, not parents (Integrity Research, 2016). As a result, any estimated effects of the ranking program were arguably driven by school and district responses, rather than parents.

\footnotetext{
${ }^{8}$ Many of the implementation problems were due to a lack of funding (Todd and Attfield, 2017).

${ }^{9}$ During the phone surveys we asked DEOs and head teachers to provide us with their school's most recent district and national rank. Many respondents could not even provide an estimate of their ranks. For the respondents that did provide an estimate, we then compared their reports to the actual data to assess the accuracy of their reports. Respondents' accuracy was higher for district rankings compared to national rankings. More information about the data collection can be found in a report by the RISE Tanzania Country Research Team (2017).
} 
In Tanzania's partially decentralized education system, there are many possible channels through which public sharing of district ranks can improve school performance, even when parental awareness is limited. DEOs faced substantial pressure to demonstrate improvement in their districts. ${ }^{10}$ DEOs receive funds from the central government to finance services and projects, and are also responsible for monitoring, staff allocations, and the transfer of capitation grants to schools. ${ }^{11}$ In principle, they could use the district ranks to re-allocate resources towards under-performing schools, provide additional support, or place pressure on schools to improve. Our interviews with DEOs revealed that some DEOs would gather all head teachers in a room and publicly berate bottom-ranked schools, and a recent report provides anecdotal evidence that some DEOs organized additional training on how to conduct remedial and exam preparation classes (Integrity Research, 2016). For their part, head teachers - driven by career concerns, professional norms, or competition with other district schools - could have taken a variety of steps to improve exam performance in order to demonstrate their competence and work ethic to their peers or superiors. Though our data will not allow us to test among alternative - and potentially complementary - channels, we will analyze the impacts of school-level responses on learning, and several margins through which this might be achieved, in Section 5 .

\section{$3 \quad$ Data and descriptive statistics}

We compiled and matched multiple sources of administrative and survey data to estimate the impact of the BRN school ranking initiative on primary school outcomes. To begin, we scraped the National Examinations Council of Tanzania (NECTA) website for school-level data on performance in the Primary School Leaving Examination (PSLE). The data includes average school test scores and national and district rankings for all primary schools from 2011 to 2016, linked over time. We do not have access to student-level or subjectspecific scores, or any data prior to 2011. ${ }^{12}$ In addition to test scores, the NECTA dataset also contains information on the number of test takers at each school, the number of students who passed the exam, and the pass rate for the school - although these measures are only available for the years 2012-2016.

We augment the data on PSLE test scores with administrative data from the Education Management

\footnotetext{
${ }^{10}$ A DFID report concluded that "[t]here was a clear sense that... district officials would be held accountable for these pass rates, with some officials stating that BRN should stand for Better Resign Now because they did not believe it would be possible to achieve these ambitious targets with their current level of resourcing" (Todd and Attfield, 2017, p. 22).

${ }^{11}$ Prior to 2016, the central government sent capitation grants to districts, which then transferred these funds to schools. According to government policy, each school was supposed to receive 10,000 Tanzanian shillings (Tsh) per student per year, roughly US\$ 4.5), but in practice there was wide variation in the amount disbursed and uncertainty over the disbursement schedule (Twaweza, 2010, 2013).

${ }^{12}$ The government issued schools with a unique ID for examination purposes. To validate that this ID consistently relates to the same school over time, we also performed a fuzzy merge by school location and school name, across all the years for which we have data. We identified a small number of schools where the unique IDs were "recycled" from schools that had closed down, or where the unique ID did not consistently relate to the same school. We constructed our own unique IDs for these cases.
} 
Information System (EMIS), which contains data on student enrollment and the number of teachers for all schools in 2015 and 2016. ${ }^{13}$ Since EMIS uses a different unique identifier, we manually matched schools from EMIS to NECTA data, using information on school location and school name. We were able to match 98.9 and 99.7 percent of schools from the NECTA data in 2015 and 2016 respectively.

In addition, we use micro-data from the World Bank Service Delivery Indicators (SDI) survey in Tanzania to supplement our analysis. The SDI is a nationally-representative panel survey of 400 schools in Tanzania collected in 2014 and 2016 (World Bank, 2016a). ${ }^{14}$ The survey measures teaching practices, teacher absence, and school resources. In addition, these data include the results of a learning assessment administered to a representative sample of fourth graders in SDI schools.

Table 1 shows basic descriptive statistics of our different data sources: NECTA, EMIS, and SDI. The NECTA data in Panel A show that average test scores and national pass rates, both computed at the school level, dropped dramatically from 2011 to 2012, but steadily increased from 2013 to 2016. Despite population growth, and an expansion in the number of primary schools from 15,000 in 2011 to over 16,000 in 2016, our data show the number of test-takers monotonically decreased from 2011 to 2015, with only a small increase in 2016 relative to $2015 .{ }^{15}$ Over our study period, the government increased the number of districts from 136 in 2011 to 184 in 2016. ${ }^{16}$ Due to this re-districting, we construct district ranks for each school using the district that the school belonged to corresponding to the PSLE exam year. ${ }^{17}$ Our results are qualitatively similar if we construct the district rank based on the district the school belongs to in the following year.

EMIS data in Panel B show that average Grade 7 enrollment is similar to the average number of testtakers the same year reported in Panel A. ${ }^{18}$ Almost all students enrolled in Grade 7 therefore end up taking the exam. The data also show a large drop in enrollment between Grades 6 and 7, implying a dropout rate of approximately 20 percent between 2015-2016.

Panel C reports results from the SDI data. Although the SDI was collected in 2014 and 2016, the reference period for certain data, such as inspections and school resources, was the previous calendar year (2013 and 2015, respectively). Other data, such as enrollment figures, were collected on a contemporaneous basis. The data show teachers were often not in their classrooms. During unannounced visits to schools in 2014, only 52

\footnotetext{
${ }^{13}$ The Ministry responsible for housing the EMIS data changed in 2015, and consequently, data prior to that year are not available.

${ }^{14}$ There is some very minor attrition in the data as we are able to match 99 percent (395/400) of schools in the SDI data to the NECTA data. Only 388 and 392 of these schools were in operation in 2012 and 2013 respectively.

${ }^{15}$ The closing down of schools is rare: 99.2 percent of schools that existed in 2011 remain in our sample in 2016.

${ }^{16}$ We account for the changes in district boundaries by including year-specific district fixed effects in our analysis. We take this approach since it better conforms to the key mechanisms such as District Education Officer actions, which would not be well captured if we aggregated our district fixed effects to the original larger districts.

${ }^{17}$ The motivation for our chosen definition is that schools face pressure to improve in the subsequent year, based on their performance in a given year. We opted for this definition because district ranks reported in a phone survey of head teachers more closely corresponded to this construction.

${ }^{18} \mathrm{On}$ average, schools had 2.6 and 0.7 more Grade 7 students enrolled than exam-sitters in 2015 and 2016 respectively. The 2016 data is more reliable.
} 
percent of teachers were in their classrooms; this improved slightly to 59 percent in 2016. Capitation grant receipts by schools rose from just over TSh 5,000 per student in 2013 to almost TSh 6,000 per student in 2015. This is substantially lower than the stated government policy of providing schools with grants of TSh 10,000 per student per year. In addition, there is a high degree of variation in the amount of grant funding received: 8 percent of schools reported that they had received the full amount, and 4 percent reported that they had received nothing. Finally, the data show that schools were inspected on average 1.56 and 1.45 times in 2013 and 2015 respectively, and roughly 70 percent of schools received at least one inspection.

\section{Empirical strategy}

We exploit the differential pressure exerted by BRN on schools at the low end of their district ranking to test for and estimate the impacts of BRN's district ranking initiative on school outcomes. This strategy addresses a fundamental challenge to evaluating the school ranking program, as all schools in the country were simultaneously exposed to this policy. In this respect, our approach is similar in spirit to recent papers that adopt such a strategy to evaluate the effects of accountability reforms in the U.S. context (Chiang, 2009; Dee and Wyckoff, 2015; Figlio and Rouse, 2006; Reback et al., 2014; Rockoff and Turner, 2010; Rouse et al., 2013). Using a panel dataset comprising the universe of primary schools and spanning multiple years both before and after the reform, we estimate the impact of BRN school rankings with a difference-in-differences model. This allows us to test and account for possible consequences of district ranks in the pre-BRN period.

Our empirical strategy exploits the remarkable across-district heterogeneity in test scores. Two schools (in different districts) with the same average test scores could have very different district rankings due to this heterogeneity. This allows us to identify the effects of a school's within-district ranking separately from its absolute performance. Naturally, absolute performance levels (or average test scores) are a potential confound for the effects of within-district rank; not only do absolute performance levels contain information about persistent aspects of school quality, but it may also be the case that schools that perform (say) poorly in absolute terms in a given year may rebound in the subsequent year due to mean reversion. As illustrated in Appendix Figures A.1, the heterogeneity across Tanzania's districts creates almost complete overlap in the support of district rankings at several values of absolute test scores in each of the years from 2011-2016. In 2011, for example, a school with the national average mean PSLE score of 111 could have ranged from being in the bottom 5 percent of schools in its district to being in the top 5 percent of schools, depending on the district in which it was located. This allows us to condition flexibly on absolute test scores while estimating the effects of district rankings. This set of flexible controls allows school test scores to follow different paths from year to year, as the relationship between test scores in year $t-1$ and $t$ is allowed to 
vary with $t$.

Given this variation, we use a difference-in-differences model to estimate the impact of being in the extreme deciles of the district ranking in the post-BRN period on schools' exam performance in the subsequent year. This specification is provided in Equation (1):

$$
y_{s d t}=f_{t}\left(y_{s, t-1}\right)+\sum_{q \in\{1,2,9,10\}} \alpha_{q} I_{q}\left(r_{s, t-1}\right)+\sum_{q \in\{1,2,9,10\}} \beta_{q} \text { Post }_{t} \cdot I_{q}\left(r_{s, t-1}\right)+\gamma_{d t}+e_{s d t} .
$$

Here, $y_{s d t}$ is the mean exam performance (test score) of school $s$ in district $d$ and year $t$. The function $f_{t}\left(y_{s, t-1}\right)$ represents a set of year-specific flexible controls for the lagged test score (up to a fourth order polynomial) of school $s$. We allow this relationship between past and current performance to vary year-byyear, to account for possible differences in the scaling and predictive content of each year's exams. We denote by $r_{s, t-1}$ the within-district rank of school $s$ in the prior year. $I_{q}$ is an indicator function that is equal to 1 if a school is ranked in decile $q$ in its district, and Post $t$ indicates whether the outcome is in the post-reform period. ${ }^{19}$ We include district-by-year fixed effects, $\gamma_{d t}$, and $e_{s, d, t}$ denotes an idiosyncratic error term. In this and subsequent specifications, we cluster the standard errors at the district level to allow arbitrary patterns of correlation across schools within a district or within schools over time.

The difference-in-differences model in Equation (1) compares the relationship between within-district school rankings and subsequent school outcomes in both post-BRN periods with the same relationship in the pre-BRN period. In both the pre- and post-BRN period, we compare performance in the bottom two deciles of district ranks with that of schools falling in the middle 60 percent of schools. Although our empirical specification includes indicators for both bottom and top ranked schools, we focus our discussion on the results pertaining to the bottom ranked schools for conciseness. ${ }^{20}$ We attribute the impact of the BRN reform only to the difference in the estimated relationship between ranks and subsequent performance for the pre- versus post-BRN periods. This is estimated by the set of parameters $\beta_{q}$.

A correlation between district rank and subsequent-year PSLE performance in the pre-reform period might arise for several reasons. DEOs might have exerted pressure on bottom-ranked schools even before BRN was introduced, and schools may have also been intrinsically motivated to improve their performance. In the specification of Equation (1), these relationships are captured in the estimated pre-reform ranking effects, $\alpha_{q}$. Although this model (due to the inclusion of lags) can only be estimated for one pre-reform year,

\footnotetext{
${ }^{19}$ An un-interacted Post $_{t}$ indicator would be absorbed by the combination of our controls. Therefore we do not include it in our specification.

${ }^{20}$ Our interest here is primarily in impacts of BRN-related exposure on low-ranked schools, but by including indicators for the top two deciles, we avoid relying on the assumption that these can be pooled with schools in the middle of their district distribution. To demonstrate that point estimates are not driven by this choice of category, we also present results graphically where only the fifth and sixth decile serve as the omitted category in Figure 1. We use the parsimonious specification to increase the statistical power of our analysis, but this choice does not substantively effect point estimates.
} 
it does allow a useful test. Specifically, if the pre-reform rank effects, $\alpha_{q}$, are jointly insignificant, then this would suggest that within-district ranks had little empirical consequence prior to the reform.

For a set of secondary, exam-related outcomes - the pass rate, number passed, and number of examsitters - we have data for one only one pre-reform period (2012), so cannot control for the lagged dependent variable when estimating a difference-in-difference model. In these cases, we continue to control flexibly for lagged average exam scores, $f_{t}\left(y_{s, t-1}\right)$, as in model (1), to identify the effect of district rank separately from absolute academic performance. To address any remaining potential confounds from persistent schoolspecific characteristics, such as the size of the school's catchment population, we augment this model to allow for school fixed effects, to estimate

$$
x_{s d t}=f_{t}\left(y_{s, t-1}\right)+\sum_{q \in\{1,2,9,10\}} \alpha_{q} I_{q}\left(r_{s, t-1}\right)+\sum_{q \in\{1,2,9,10\}} \beta_{q} \text { Post }_{t} \cdot I_{q}\left(r_{s, t-1}\right)+\gamma_{d t}+\mu_{s}+e_{s d t} .
$$

In this specification, $x_{s d t}$ are these secondary outcomes, and $\mu_{s}$ refers to school-level fixed effects. These school fixed effects absorb any time-invariant sources of correlations between schools' district ranks and the outcome of interest that might not be fully captured by the lagged test score. Standard errors for this specification are also clustered at the district level.

Finally, we use SDI and EMIS data on a range of outcomes, such as enrollment, school resources, and teacher absences, to test for mechanisms. Each of these datasets contains multiple years of data, but they do not contain data from the pre-reform period. In these cases we estimate a fixed-effects model of the form in Equation (2). While we are unable to difference out the pre-reform ranking effects, q, we continue to control flexibly for lagged test scores in order to isolate a plausible causal effect of district rankings, taking advantage of the fact that schools with the same test score can have different rankings in alternative districts. ${ }^{21}$ Conservatively, the estimates for these outcomes can be interpreted as the sum of pre-reform ranking effects and the post-reform change (i.e., $\alpha_{q}+\beta_{q}$ from Equation (1)). If the pre-reform coefficients, $\alpha_{q}$, are truly zero for these outcomes, then these estimates can be interpreted as BRN effects. Our confidence in this assumption will be strengthened to the extent that pre-reform ranking effects, $\alpha_{q}$, are jointly insignificant for test score outcomes. We can also be more confident in this assumption if we find similar results in closely related but longer time series. For example, we can compare and confirm that the results using the number of exam takers as an outcome are comparable to those using enrollment as an outcome (see Table 3). Moreover, in Section 6, we will present tests that split the sample by school size in both double-difference and singledifference models, to test for mean reversion; we find no evidence that effects are stronger for smaller schools,

\footnotetext{
${ }^{21}$ Reback et al. (2014) use a similar empirical strategy to evaluate the accountability pressure generated by the No Child Left Behind reforms in the US.
} 
where mean reversion would is expected to be stronger (Kane and Staiger, 2002).

\section{Results}

Below we present results for impacts of the reform. After providing evidence that BRN improved exam results for schools in the bottom of their district ranks, we explore several mechanisms that may underlie this result. We test for impacts on the number of test-takers and on enrollment, finding evidence consistent with BRN-induced drop-out. We find no evidence of impact on a range of educational inputs or on learning in lower grades.

\subsection{Pressure on low-ranked schools improves low-ranked schools' average exam performance and pass rates}

Figure 1 illustrates the basis for the difference-in-difference estimates, focusing on the estimation of Equation (1) for two main outcomes of interest: the average PSLE score - which is the basis for the ranking itself - and pass rate - which motivated the adoption of the reform. In Figures 1(a) and 1(c), we show estimates and 90 percent confidence intervals for the impacts of being in decile $q$ of the district rank, relative to the schools between the 40th and 60th percentile in their district, on a school's average test scores and pass rates, respectively, in the subsequent year. We estimate coefficients separately for the pre-reform period (the light lines and squares, corresponding to parameters $\alpha_{q}$ in Equation (1)) and post-reform periods (the dark lines and circles, corresponding to the sum of parameters $\alpha_{q}+\beta_{q}$ ). Estimates control for a fourth-order polynomial in the absolute lagged test score, as well as district-year indicators. Our estimates of the consequences of the reform for the relative performance of bottom- and top-performing schools within their districts is given by the difference between these pre- and post-reform ranking coefficients. These differences, and associated confidence intervals, are shown directly in Figures 1(b) and 1(d).

There is no statistically significant relationship between within-district ranks and subsequent performance in the pre-BRN period. As Figures 1(a) and 1(c) illustrate, point estimates are closer to zero for the preperiod. Regression estimates of Equation (1) confirm that these pre-BRN ranking effects are both individually and jointly insignificant. An $F$ test for the joint significance of the coefficients $\alpha_{q}$ fails to reject the null that they are equal to zero, with a $p$-value of 0.28 and 0.78 when the outcome variable is the average score and the pass rate respectively. We do not need to assume these pre-reform ranking effects are zero to identify test score impacts, since the difference-in-difference specification of Equation (1) would also difference out any pre-reform relationship. ${ }^{22}$ But given that our analysis of potential mechanisms will rely on datasets that

\footnotetext{
${ }^{22}$ If this differences-in-differences approach, combined with the flexible control for lagged test scores, failed to address mean
} 
do not include the pre-reform period, this absence of a pre-reform relationship strengthens our confidence in a causal interpretation of those estimates as well.

In Column (1) of Table 2, we present regression estimates of our primary difference-in-differences model from Equation (1), for the impacts of post-BRN district rankings on subsequent average exam scores. The first two rows present our main coefficients estimates, $\beta_{q}$, which compare differential post-BRN outcomes for schools in the bottom two deciles to schools in the middle six deciles of their district. These results indicate that being in the bottom decile in the post-BRN period is associated with a rise of more than four points on the average PSLE mark in the subsequent year, relative to schools in the middle six deciles, over and above any relationship that existed in the pre-reform period. This corresponds to an impact of just over 0.25 standard deviations in the distribution of school means for bottom-decile schools - a substantial effect size for what is essentially an informational intervention. ${ }^{23,24}$ There is a smaller, but still statistically significant impact for schools in the second decile of school performance. ${ }^{25}$

Columns (3) through (6) of Table 2 expand these results to two additional metrics of exam performance: the pass rate and the number passed. We first discuss the results in the odd-numbered columns, which are estimated using our main specification, Equation (1). The impacts on pass rates, shown in Column (3), are substantial. The estimated impact of 5.77 percentage points for schools in the bottom decile implies a 38 percent increase relative to the pre-BRN pass rate of 15 percent among bottom-decile schools. In Column (5), we find that the reform increased the number of students that passed the PSLE by 1.8 students - a 21 percent increase relative to the pre-BRN level. ${ }^{26}$ In Appendix Table B.3, we show that these BRN-induced increases in exam scores also translate into reductions in the probability that schools in the bottom decile or quintile remain in that group in the subsequent year.

As a robustness check, the even-numbered columns show results on each measure of exam performance, estimated using the school fixed-effects model of Equation (2). It is encouraging that each of these results remain qualitatively unchanged. The coefficients for all three outcomes are, in fact, slightly larger and the results on number passed are also now more precisely estimated. ${ }^{27}$ This provides us more confidence to use this specification in subsequent analyses where data unavailability prevents us from constructing the lags of

reversion in the post-reform period, then one would expect to see stronger effects in smaller schools, where the variance of average test scores is greater (Kane and Staiger, 2002). As we will show in Table 5, if anything, larger schools exhibit stronger effects.

${ }^{23}$ Pre-BRN Summary statistics for each performance decile are available in Appendix Table B.2.

${ }^{24}$ See, for example, McEwan (2013) for a review. All families of interventions studied there have average effect sizes smaller than 0.2 standard deviations on student-level test scores.

${ }^{25}$ Figure 1 shows that there are no detectable differences among schools that fall in the middle six deciles, in a specification that allows different effects for each decile. This affirms our decision to compare the extreme deciles with schools in the middle $60 \%$, rather than only the middle $20 \%$, for reasons of statistical power.

${ }^{26}$ The pre-BRN summary statistics are available in Appendix Table B.2.

${ }^{27}$ This is because lagged test scores are not as highly correlated with the number passed, compared to average score. Note that the R-squared in Column (5) is lower than in columns (1) and (3). The introduction of fixed effects allows us to mop up additional variation. 
dependent variables.

\subsection{Pressure on low-performing schools decreases test-takers and enrollment}

Although our estimates show that school-ranking initiative lead to increases in learning for (some) students in bottom-ranked schools, schools could have artificially boosted their average exam scores by strategically reducing the number of students who sit the exam. Here, we test for and estimate this mechanism directly.

In Column (1) of Table 3, we estimate BRN ranking impacts on the number of exam-sitters, using Equation (2). Schools that fell in the bottom decile in their district have over two fewer test-takers the following year, compared to schools that fell in the middle six deciles. This equates to roughly a 4 percent reduction in the number of test-takers, since the average number of test-takers in the pre-BRN period in bottom quintile schools is $47 .{ }^{28}$ Likewise, schools in the second-to-bottom decile also appear to reduce the number of test takers by nearly two students. ${ }^{29}$

We next explore the fate of the students who were excluded from testing due to the BRN school rankings initiative. The answer is important to the welfare implications of the BRN ranking. We consider three possibilities: students could have repeated Grade 6 in the same school, switched to a different (potentially better) school, or dropped out of school altogether. The welfare loss of fewer exam-sitters will be greater if the reduction is driven primarily by students dropping out, rather than switching schools or repeating Grade 6.

To test whether BRN-induced pressure led to greater repetition rates, we apply Equation (2) with gradespecific enrollment numbers from EMIS data as the outcome (see columns (3)-(6) in Table 3). Because EMIS data are only available for the years 2015 and 2016, we are not able to estimate this relationship in the pre-BRN period. However, we continue to take advantage of the fact that schools with the same test score can have different rankings in other districts, in order to identify a plausible causal effect of district rankings (see Reback et al. (2014) for more details on this identification strategy). In this specification, we impose that the relationship between rankings and subsequent outcomes was flat in prior to BRN, implying coefficients $\alpha_{q}=0$, for all quantiles $q$. To shed light on whether this restriction is likely to be consequential, we first re-estimate impacts on the number of test-takers, restricting attention to 2015-2016 and therefore only using post-BRN data. As shown in Column (2) of Table 3, the estimated impacts on test-takers remains statistically

\footnotetext{
${ }^{28}$ The pre-BRN summary statistics are available in Appendix Table B.2. Appendix Table B.7 shows that these impacts are borne equally by male and female students.

${ }^{29}$ Not shown in the table, we also find marginally significant impacts on schools at the top of the distribution, though in the opposite direction - for schools in the top decile of their district distribution, there is a marginally statistically significant increase of over 1.6 students in the following year. There is no statistically significant change in test takers in the second highest decile. Given that this is not mirrored in enrollment figures, and that it is the only statistically significant finding on enrollment outcomes for the top two deciles, out of 10 coefficients estimated, we do not place much emphasis on interpretation of this finding. As will be shown in our analysis of enrollment sorting within schooling markets below, we also see no evidence of outflows from poorly performing schools to better nearby schools.
} 
significant, although slightly smaller in magnitude. ${ }^{30}$ This adds to our confidence that the assumption that pre-reform ranking effects on EMIS outcomes are zero, or that violations of this assumption appear likely to attenuate observed results for enrollment-related outcomes.

In Column (5) of Table 3, we show that estimated impacts on Grade 7 enrollment are similar to those observed for PSLE exam taking. In particular, the estimated loss of more than 1.6 students in Grade 7 mirrors almost exactly the effect size estimated on exam takers for data from the same period. ${ }^{31}$ However, Column (4) shows that there is no concurrent increase in Grade 6 enrollment in these same schools. We therefore find no evidence that these students are merely repeating Grade 6-they are either dropping out, or switching schools.

Next, two tests allow us to rule out the interpretation that students are switching to other, potentially better-performing schools. First, we estimate the impact on enrollment in earlier grades. If students switched out of low-ranking and into high-ranking schools in their district because they updated their beliefs about school quality, then this effect need not be limited to Grade 7. Students in earlier grades could also be induced to switch as well. However, we have already seen in Column (4) of Table 3 that there is no evidence of an enrollment impact in Grade 6. To provide an additional — and potentially more powerful — test for such a phenomenon, we estimate impacts of within-district deciles on the pooled numbers of students in Grades 4-6. As shown in Column (3) of Table 3, there is no evidence that the enrollment effects observed in Grade 7 are also found in lower grades. ${ }^{32}$

Second, we test if school enrollment is also a function of neighboring schools' performance. If Grade 7 students from schools in the bottom decile of their district are switching to other schools, then there should be a positive effect on Grade 7 enrollment of being surrounded by schools that perform poorly. To operationalize this, we use a school's ward designation - a geopolitical unit just below the district that contains on average four schools-to define a local school 'market.' Wards are good approximations for school markets because they are typically used to define catchment areas for secondary schools. We then augment the specification used in Table 3 by including ward means of the within-district decile indicators, to estimate an equation of

\footnotetext{
${ }^{30}$ Note that it is entirely possible that the true treatment effect of BRN is smaller in these later years, as the reform was losing momentum.

${ }^{31}$ These results suggest that the test-taking results are not simply due to students being absent from school during the testing period. Rather, the students are not enrolling in Grade 7.

${ }^{32}$ Given the salience of the PSLE, it is likely much harder to switch schools at Grade 7 (relative to earlier grades) as schools would be reluctant to admit students who may perform poorly on the PSLE. Thus, we would expect greater switching to occur in earlier grades. The fact that we do not find any evidence of school switching suggests that either there is insufficient school choice or that parents were not sufficiently informed.
} 
the form:

$$
\begin{aligned}
x_{s w d t}= & f_{t}\left(y_{s, t-1}\right)+\sum_{q \in\{1,2,9,10\}} \alpha_{q} I_{q}\left(r_{s w, t-1}\right)+\sum_{q \in\{1,2,9,10\}} \beta_{q} I_{q}\left(r_{s w, t-1}\right) \cdot \text { Post }_{t} \\
& +\sum_{q \in\{1,2,9,10\}} \phi_{q} \bar{I}_{q w, t-1}+\sum_{q \in\{1,2,9,10\}} \pi_{q} \bar{I}_{q w, t-1} \cdot \text { Post }_{t}+\gamma_{d t}+\mu_{s}+e_{d s t}
\end{aligned}
$$

As before, $x_{s w d t}$ denotes enrollment in school $s$, which is in ward $w$ and district $d$, in year $t$. The key difference in relation to Equation (2) is that we include ward-level means of the district rank indicators (or the share of schools in the ward within each district rank), defined as $\bar{I}_{q w, t-1}=\frac{1}{|w|} \sum_{s \in w} I_{q}\left(r_{s w, t-1}\right)$, where $|w|$ is the number of schools in ward $w$. We include these directly and interacted with a post-BRN indicator. Coefficients $\pi_{q}$ capture BRN-induced sorting in enrollment- that is, induced transfers to other schools within the ward.

If all BRN-induced exits from schools are in fact transfers to other schools in the same ward, then we would expect the coefficients on ward averages of the district rank indicators to be equal in magnitude and opposite in sign to the corresponding school-level effects, so that $\beta_{q}+\pi_{q}=0$ for each district ranking decile, $q .{ }^{33}$ For example, recall that we estimate, in Table 3, that a school in the bottom decile of its district will be induced to shed two test takers in the following year. If these were purely transfers, then we would expect the sorting coefficient $\left(\pi_{q}\right)$ for the bottom decile to equal two. On the other hand, if there were no BRN-induced transfers, then the coefficients on ward means would be equal to zero.

Estimates of Equation (3), presented in Appendix Table B.4, suggest that enrollment sorting is not important here. We are able to reject the implication of the pure sorting model, that $\beta_{q}+\pi_{q}=0$ for all $q$, with a $p$ value of 0.054 . Point estimates for the share of ward means in the bottom decile - where we see induced drop-outs - are negative, rather than positive, as would be predicted by an empirical model of pure sorting. Moreover, the sorting coefficients, $\pi_{q}$, are always statistically insignificant.

Taking this direct test of sorting together with the absence of enrollment effects on lower grades, we conclude that the estimated impact of receiving a low district ranking on the number of test takers (and enrollment) is unlikely to be driven by strategic grade repetition or by students switching schools away from low-ranked schools. Instead, it appears that the pressure of receiving a low ranking in the district leads schools to respond by inducing some students who would otherwise enroll in this exam-taking year to drop out altogether.

\footnotetext{
${ }^{33}$ Intuition for the coefficients on these ward-level means, $\bar{I}_{q w, t-1}$, can be understood by comparison with estimation of the analog of Equation (2) entirely at the ward level, as in Hsieh and Urquiola (2006). In such a ward-level regression, we would expect the coefficients on ward averages of the district rank indicators to be equal to zero if the school-level impacts of district rank on the number of takers had been purely driven by students switching schools. But for each decile $q$ of district ranking, the coefficients on the corresponding ward-level averages, $\bar{I}_{q w, t-1}$ are equivalent to the sum of coefficients on school indicators, $\beta_{q}$, and their corresponding ward averages, $\pi_{q}$, in Equation (3). Consequently, a case in which BRN induces pure student switching across schools would be a case in which $\beta_{q}+\pi_{q}=0$.
} 
As the number of excluded students is relatively small, we examine the extent to which this strategy could have driven the observed increase in schools' average test scores. To do so, we re-estimate the analysis of the program's effect on test scores (Column (1) of Table 2), bounding the consequences of the exclusion effect. Specifically, we can compute the adjusted school's average test score by adding back the excluded students (using the coefficients in Table 3), and making an assumption about what these students would have scored on the PSLE. The positive and significant test score effects hold unless the excluded students had PSLE average test scores below 27 (out of 250). This level of performance is approximately equivalent to the average performance of the worst school in the data. ${ }^{34}$ Thus, our analysis shows that exclusion of just two students can meaningfully inflate a school's average test score - giving school administrators an incentive to pursue this strategy — especially if schools can correctly identify students who are likely to fail.

This strategy of exclusion only affects the school's average test score and pass rate. It will not directly affect the absolute number of students who pass the PSLE. ${ }^{35}$ Thus, our results on the absolute number of students passing the PSLE are not an artifact of such gaming, and are instead a reflection of real improvements in learning. Taken together, our results on the number passed and the number of test takers suggest that low-ranked schools responded to the BRN district ranking initiative by both excluding students and also exerting effort to raise the performance of the remaining students.

\subsection{No evidence of impacts on monitoring, resources, teacher effort, or learning in other grades}

We next turn to examining potential mechanisms underlying the estimated improvements in exam performance. Schools at the bottom deciles could have improved performance if they received more resources from government or the community, used existing resources more efficiently, increased overall levels of teaching effort, or re-allocated existing resources and efforts towards preparing Grade 7 students for the exams. In this sub-section, we use the World Bank Service Delivery Indicators (SDI) panel dataset to test for some of these mechanisms: specifically, these data allow us to test for impacts on numbers of teachers, stocks of textbooks, school finances, district inspections, and teacher presence. SDI data from a sample of Grade 4 pupils further allow us to test for learning impacts on earlier grades.

As a starting point for this analysis, we show that the main results hold with the reduced sample of schools and years in which the SDI data collection took place. Appendix Table B.5 replicates the main results for the reduced sample and the years corresponding to the SDI outcomes: 2013-2016. ${ }^{36}$ The estimated impacts

\footnotetext{
${ }^{34}$ In this school all students failed and received the worst possible letter grade ("E") on the PSLE.

${ }^{35}$ There could be indirect effects of strategic exclusion on the number passed. Potential pathways include reductions in class size and reductions in within-classroom heterogeneity.

${ }^{36}$ Data collection data took place in 2014 and 2016. However, some questions - such as receipt of resources and school
} 
for this sample are in fact much higher, and remain statistically significant.

Columns (1) to (3) in Table 4 show that bottom-decile schools did not receive any more resources from government. ${ }^{37}$ There is no statistical significant difference in the number of teachers, the number of textbooks (per student), or the per student value of capitation grants received over the year. ${ }^{38}$ Thus, we do not find evidence that schools faced punitive consequences for poor performance.

Column (4) shows that schools were no more likely to receive a school inspection if they were in the bottom decile in the preceding year. We therefore have no evidence that government provided additional supervisory or support visits to schools. This does not conclusively rule out top-down pressure from the district officials, though, since inspections are performed by the Quality Assurance Department of the Ministry of Education, and this variable does not capture visits by the District or Ward Education Officers. In addition, these data do not capture other potential methods education officials could have used pressure schools, such as the stakeholder meetings documented in the qualitative reports (Integrity Research, 2016).

Column (5) shows that there is no statistically significant impact on teacher presence Thus, it is unlikely that increases in school-presence among teachers could have driven the observed learning gains.

However, this leaves open the question about the means used by schools to improve learning outcomes. It is possible that schools responded to the pressure by offering remedial courses, or spending more time preparing Grade 7 students for the PSLE. Unfortunately, such forms of effort were not measured in the SDI data. ${ }^{39}$ It is also possible that the strategic removal of some students could actually cause learning outcomes to improve for those who remain, especially if those removed from class are particularly disruptive. ${ }^{40}$

SDI data also allow us to look at the impacts of the reform on student learning in other (non-incentivized) grades. The impact of the reform on learning in other grades could go in two directions. On the one hand, it is possible that increased effort levels could lead to positive spillovers on learning in earlier grades. On the other hand, learning in earlier grades could have suffered if existing school resources were redirected to students in Grade 7.

The SDI data collection included an assessment of a random sample of twenty Grade 4 students in three different subjects areas: Mathematics, English, and Kiswahili; all the measures are standardized to have a mean of zero and standard deviation of one. Appendix Table B.6 reports results on these outcomes. Although results are somewhat imprecise, there is no detectable positive or negative impact on learning.

inspections - were asked using the previous year as the reference period.

${ }^{37}$ Recall that this model is estimated with school fixed effects, and so is identified off switches in ranking status across years.

${ }^{38}$ We take an inverse hyperbolic sine transformation of the textbooks and grants.

${ }^{39}$ In general, it is very difficult to accurately capture teacher effort. However, a number of experimental studies on teacher incentives found increases in learning outcomes without any corresponding increase in teacher presence (for example see $\mathrm{Mu}-$ ralidharan and Sundararaman (2011) and Mbiti et al. (2019)). This suggests that teachers can increase effort in ways that are difficult to capture using our conventional methods.

${ }^{40}$ The reductions in class-size are arguably too small to reduce significantly reduce within-class heterogeneity. Thus, given the small reduction in the number of students, disruption effects are a plausible mechanism. 
The gains in learning are therefore likely restricted to Grade 7 students.

\section{Robustness}

The publication of within-district school rankings was only one part of a suite of reforms undertaken under the heading of Big Results Now (see Appendix Table B.1 for more details). Many of these reforms were unlikely to impact Grade 7 outcomes during study period (for example, the early grade curriculum reforms), and the implementation of most of BRN components were delayed due to the lack of funding. For example, the capitation grant reform was only launched in 2016 - the last period of our study. The school ranking program was the first component launched and one of the few that was consistently implemented throughout our study period. Other initiatives such as the Student Teacher Enrichment Programme (STEP) were implemented starting in 2014, and may drive our results. To assuage these concerns, we conduct several robustness checks.

We first examine whether our results are driven by pressure generated from national rankings or from district rankings. As Appendix Table B.1 shows, the BRN reforms included a national ranking system, and these could have been more salient than the district rankings. However, schools' national rankings are a one-to-one, monotonic increasing function of the school-level average test scores, which are already flexibly included in our specifications. Thus, our empirical specifications arguably already control for a sufficient statistic of the national ranking. However, to further assuage concerns about the potential role played by the national component of the school ranking, we conduct additional empirical checks in Table 5. First, we split our sample by the average district performance in columns 1 and 2 of Table 5. Bottom-ranked schools in below-average districts would be the worst schools nationally, while bottom-ranked schools in above-average districts would not necessarily fall in the bottom of the national rank distribution. ${ }^{41}$ Conversely, top schools in the above-average districts would be among the best schools nationally, while top schools in the belowaverage districts would not necessarily be among the best schools. To the extent that national rankings play a role in driving district-ranking results, then bottom-ranked schools in the better districts face less pressure than bottom-ranked schools in the below-average districts. Thus, we would not find any effects in Column (2). However, our results show that bottom-ranked schools in both types of districts saw subsequent increases in performance, suggesting that the district rankings were the primary driver.

In the original project design, the best performing schools would receive non-monetary rewards such as certificates, public ceremonies, and media coverage. For schools that saw the greatest improvement, the government planned to grant 3-5 million Tanzanian shillings ( US $\$ 1,800-3,000)$ to the 300 most improved

\footnotetext{
${ }^{41}$ The average performance of schools in the bottom decile within below-average districts is roughly equivalent to the $25^{t h}$ percentile of all schools, while the average school in the bottom decile within above-average districts is roughly at the median of all schools.
} 
primary schools and 1-2 million Tanzanian shillings ( US\$600-1200) to 2,700 other primary schools that were most improved (Government of Tanzania, 2014). However, despite these pledges, the government significantly scaled back the program such that by October 2016 only 120 primary schools had ever received incentive grants (World Bank, 2018a). Given that less than one percent of schools actually won such prizes, it is unlikely that our results are driven by the School Incentive Grants. Moreover, qualitative reports suggest that the incentive program was not well understood (Integrity Research, 2016).

Since the best-performing schools nationally tend to be in above-average districts, the School Incentive Grant would likely induce top schools from the better districts to respond. However, we did not find any statistically significant effects among the top schools in the best districts (coefficents not shown). In addition, schools that experienced large negative shocks in the previous year would be better placed to earn a reward as they could leverage mean reversion to boost their test score improvement metric. As discussed in more detail below, we show that our results are robust if we exclude schools that experienced large declines in test scores, suggesting that the results are not driven by the school incentives program.

The BRN program also included the Student-Teacher Enrichment Program (STEP) which was a remedial education program that was aimed at improving test scores in the PSLE. The program trained teachers across districts to identity and support low performing students who were preparing for the PSLE exam. The STEP program also trained teachers to conduct diagnostic tests to identity students who were at risk of failing. These students would receive extra remedial instruction and exam coaching sessions to prepare them for the exams (Government of Tanzania, 2014). Given the limited capacity of the government to roll-out this program across the entire country, the implementation was targeted toward districts that had large numbers of failing students in previous years, as well as districts that had experienced a large drop in performance in the pre-BRN period (Government of Tanzania, 2014, 2015). Using the implementation plan outlined in official reports (see for example (Government of Tanzania, 2014)), we identify the districts which were targeted for the STEP program, and compare the results for the STEP districts to the non-STEP districts in columns (3) and (4). Overall, we find similar results in both sets of districts, suggesting that the STEP program is not biasing our results.

An additional concern is that reversion to the mean may drive our results despite our ability to include flexible controls for past performance and district fixed effects. To address such concerns, we split our sample into different categories based on their potential to experience mean reversion. We first compare schools that experienced a large reduction in exam performance the previous year to those that did not. Specifically, we compare schools that saw a reduction of at least 30 percentile points nationally to those that did not. ${ }^{42}$ Since schools that experienced a negative shock are more likely to "bounce back", this comparison provides

\footnotetext{
${ }^{42}$ We find qualitatively similar patterns using a variety of thresholds including a 10 percentile point reduction.
} 
an additional test of the potential for mean reversion to bias our findings. We find no evidence that the treatment impacts are concentrated in schools that experienced a shock in Column (6) of Table 5. The treatment impact remains large after excluding these schools, and there is in fact no detectable impact of the reform on the subset of schools who experienced such a shock, although the sample size in Column (5) is small. We repeat this exercise using different percentile decline thresholds and find similar patterns. For instance, among the group of almost 10,000 schools that experienced a 10 percentile drop, we did not find any statistically significant effects of being in the bottom rank on subsequent performance (see Table B.8 in the Appendix).

To the extent that smaller schools both are more likely to experience mean-reversion and face stronger incentives on a 'gains' metric of school performance (Kane and Staiger, 2002), we also split the sample by school size in Column (7) and (8) of Table 5. We compare the smallest fifth of schools (Column (7)), as measured by the number of test-takers in the pre-reform period (2012) to their larger counterparts (Column (8)). We find similar results in both sets of schools, suggesting that mean reversion is not driving our results. In Appendix Table B.9, we repeat this exercise for test score outcomes using only post-reform data - that is, in a model that does not difference out pre-reform decile effects. To the extent that the ability to difference out pre-reform decile effects is important to addressing mean reversion, this might drive estimates using EMIS and SDI data from the post-reform period. However, we instead find that larger schools exhibit, if anything, stronger responses, even in this model that uses only post-reform data. These findings strengthen our confidence that mean reversion does not drive our results.

As smaller schools and schools that experienced negative shocks are also more likely to see larger performance gains in subsequent exam performance, and face stronger incentives to bring these gains about, these robustness checks also serve as additional checks about the potential for our results to be driven by the school incentive program. Since we generally find that our results are robust when we exclude small schools and schools that experienced shocks, we can be more confident that our results are primarily reflect the district ranking component of BRN.

\section{Discussion}

Tanzania's Big Results Now in Education program has been touted as a "promising society-wide collaborative [approach] to systematically improving learning" (World Bank, 2018b). With the full backing of the office of the President, the program was highly visible both nationally and internationally, and attracted US\$ 257 million in donor funds.

This study presents evidence that such low-stakes accountability programs do not provide any direct 
financial incentives can lead to improvements in performance, even in absence of a parental response. In Tanzania, there was an overall improvement in the exam performance for schools in the bottom deciles of their district, who faced additional pressure to improve. There was also a net increase in the total number passed. It is unlikely that parental responses to information provided these incentives, since parents were on the whole unaware of their school's district rank. The mechanism is most likely a combination of pressure exerted by District Education Officers, who themselves had incentives to demonstrate in their district, and a mix of professional norms and competitive desires among head teachers, seeking to avoid poor performance in an environment in which results had become more salient.

However, this study also tells a cautionary tale of the negative unintended consequences of policies. Our results show that the BRN reform had mixed effects on student outcomes. On one hand, the reform improved learning among students in bottom-ranked schools, resulting in almost two additional students passing the PSLE. On the other hand, the reform pushed out roughly two students from Grade 7 in bottom-decile schools, and evidence suggests that these students dropped out rather than repeating or switching schools. Thus, the overall welfare effect of the program is unclear and will depend on the structure of policymaker preferences.

Arguably, the value of educational gains experienced by the 1.8 students per school who were induced to pass their PSLE exam are substantial, as nearly all students who pass the PSLE progress to secondary school. ${ }^{43}$ Moreover, on average students who enter secondary school (Form 1) have a $73 \%$ chance of completing lower secondary school and receive an additional 3.8 years of schooling. ${ }^{44}$ Of course, marginal PSLE passers are likely among the least prepared students for secondary schools, and so these typical attainment levels likely represent an upper bound on those achieved by students induced to pass the PSLE by the BRN ranking.

These benefits have to be compared to the reduction in acquired human capital for the roughly 2 students per school who were excluded from the PSLE as a result of the reform. Since our analysis suggests that they dropped out of school altogether, rather than repeating a grade or transferring to another school, we conclude that these students lose the acquired human capital of Grade 7 altogether. ${ }^{45}$

Weighing these positive and negative effects, we conclude that it is likely that BRN's public ranking of schools resulted in a net increase in total grade attainment in schools ranking in the bottom of their districts, but that this came at the expense of losses in the human capital of low-performing students. An

\footnotetext{
${ }^{43}$ The number of students enrolled in the first year of secondary school typically exceeds the number of students passing the PSLE in the prior year.

${ }^{44}$ The transition rates between the years 2016 and 2017 for Grade 9 (Form 2) to Grade 13 (Form 6) were $97 \%$, $83 \%, 91 \%$, $22 \%$, and $95 \%$ respectively.

${ }^{45}$ Because estimated impacts on the absolute number of PSLE passers are net of these dropouts, any continuation value of subsequent years of schooling by those induced to drop out is already accounted for above.
} 
inequality-averse policymaker may reject this tradeoff in spite of the positive effect on average years of schooling.

Nonetheless, this reform highlights that even reputational incentives - if they are sufficiently powerful to induce a behavioral response - can induce strategic responses that are inconsistent with policymakers' intent. School stakeholders respond to incentives on the margins they they judge most effective. The consequences of those behavioral responses can be a double-edged sword. 


\section{References}

Andrabi, Tahir, Jishnu Das, and Asim Ijaz Khwaja, "Report cards: the impact of providing school and child test scores on educational markets," American Economic Review, 2017, 107 (6), 1535-1563.

Baker, George, "Distortion and risk in optimal incentive contracts," Journal of Human Resources, Fall 2002, $37(4), 727-751$.

Baker, George P, "Incentive contracts and performance managent," Journal of Political Economy, 6 1992, $100(3), 596-614$.

Banerjee, Abhijit V, Rukmini Banerji, Esther Duflo, Rachel Glennerster, and Stuti Khemani, "Pitfalls of participatory programs: Evidence from a randomized evaluation in education in India," American Economic Journal: Economic Policy, 2010, 2 (1), 1-30.

Bold, Tessa, Mwangi Kimenyi, Germano Mwabu, Alice Ng'ang'a, and Justin Sandefur, "Experimental evidence on scaling up education reforms in Kenya," Journal of Public Economics, December $2018,168,1-20$.

Bruns, Barbara, Deon Filmer, and Harry Anthony Patrinos, Making schools work: New evidence on accountability reforms, Washington, D.C.: The World Bank, 2011.

Burgess, Simon M, Carol Propper, Helen Slater, and Deborah Wilson, "Who wins and who loses from school accountability? The distribution of educational gain in English secondary schools," CEPR Discussion Paper No. 5248 September 2005.

Camargo, Braz, Rafael Camelo, Sergio Firpo, and Vladimir Ponczek, "Information, market incentives, and student performance: Evidence from a regression discontinuity design in Brazil," Journal of Human Resources, 2018, 53 (2), 414-444.

Chay, Kenneth Y, Patrick J McEwan, and Miguel Urquiola, "The central role of noise in evaluating interventions that use test scores to rank schools," American Economic Review, 2005, 95 (4), 1237-1258.

Chiang, Hanley, "How accountability pressure on failing schools affects student achievement," Journal of Public Economics, October 2009, 93 (9-10), 1045-1057.

Craig, Steven G, Scott A Imberman, and Adam Perdue, "Does it pay to get an A? School resource allocations in response to accountability ratings," Journal of Urban Economics, 2013, 73 (1), 30-42. 
Craig, Steven G., Scott A. Imberman, and Adam Perdue, "Do administrators respond to their accountability ratings? The response of school budgets to accountability grades," Economics of Education Review, 12 2015, 49, 55-68.

Dee, Thomas and James Wyckoff, "Incentives, selection, and teacher performance: Evidence from IMPACT," Journal of Policy, 2015, 34 (2), 267-297.

Figlio, D and C. E. Rouse, "Do accountability and voucher threats improve low-performing schools?," Journal of Public Economics, 2006, 90 (1-2), 239-255.

Figlio, David and Susanna Loeb, "School accountability," in Eric A Hanushek, Stephen Machin, and Ludger Woessmann, eds., Handbook of the Economics of Education, North Holland, 2011, chapter 8, pp. 383-421.

Figlio, David N, "Testing, crime, and punishment," Journal of Public Economics, 2006, 90, 837-851.

_ and Lawrence S Getzler, "Accountability, ability, and disability: Gaming the system," NBER Working Paper No. 9307 November 2002.

Glewwe, Paul, Nauman Ilias, and Michael Kremer, "Teacher incentives," American Economic Journal: Applied Economics, July 2010, 2 (3), 205-227.

Government of Tanzania, "Big Results Now! Education Lab storyline," Presidential Delivery Bureau 2014.

_ , "Big Results Now! Annual report 2013/14," Presidential Delivery Bureau 2015.

Hanushek, Eric A and Margaret E Raymond, "Does school accountability lead to improved student performance?," Journal of Policy Analysis and Management: The Journal of the Association for Public Policy Analysis and Management, 2005, 24 (2), 297-327.

Hastings, Justine S and Jeffrey M Weinstein, "Information, school choice, and academic achievement: Evidence from two experiments," The Quarterly Journal of Economics, 2008, 123 (4), 1373-1414.

Holmstrom, Bengt and Paul Milgrom, "Multitask principal-agent analyses: Incentive contracts, asset ownership, and job design," Journal of Law, Economics, and Organization, January 1991, 7, 24-52.

Integrity Research, "P4R analysis of the Tanzania School Ranking Initative," 2016. Report Submitted to Cambridge Education. 
Jacob, Brian A, "Accountability, incentives, and behavior: the impact of high-stakes testing in the Chicago Public Schools," Journal of Public Economics, June 2005, 89, 761-796.

Jones, Sam, Youdi Schipper, Sara Ruto, and Rakesh Rajani, "Can your child read and count? Measuring learning outcomes in East Africa," Journal of African Economies, 2014.

Joshi, Arun R and Isis Gaddis, Preparing the next generation in Tanzania: Challenges and opportunities in education, The World Bank, 2015.

Kane, Thomas J and Douglas O Staiger, "The promise and pitfalls of using imprecise school accountability measures," Journal of Economic Perspectives, 2002, 16 (4), 91-114.

Koning, Pierre and Karen van der Wiel, "School responsiveness to quality rankings: An empirical analysis of secondary education in the Netherlands," De Economist, Dec 2012, 160 (4), 339-355.

_ and Karen Van der Wiel, "Ranking the schools: How school-quality information affects school choice in the Netherlands," Journal of the European Economic Association, 2013, 11 (2), 466-493.

Lieberman, Evan S., Daniel N. Posner, and Lily L. Tsai, "Does information lead to more active citizenship? Evidence from an education intervention in rural Kenya," World Development, 2014, 60 (Supplement C), $69-83$.

Mbiti, Isaac, Karthik Muralidharan, Mauricio Romero, Youdi Schipper, Constantine Manda, and Rakesh Rajani, "Inputs, incentives, and complementarities in education: Experimental evidence from Tanzania," The Quarterly Journal of Economics, August 2019, 134 (3), 1627-1673.

McEwan, Patrick J, "Improving learning in primary schools of developing countries: A meta-analysis of randomized experiments," Working paper, Wellesley College August 2013.

Mizala, Alejandra and Miguel Urquiola, "School markets: The impact of information approximating schools' effectiveness," Journal of Development Economics, 2013, 103, 313-335.

Muralidharan, Karthik and Paul Niehaus, "Experimentation at scale," Journal of Economic Perspectives, 2017, 31 (4), 103-124.

- and Venkatesh Sundararaman, "Teacher performance pay: Experimental evidence from India," Journal of Political Economy, February 2011, 119 (1), 39-77.

Neal, Derek and Diane Whitmore Schanzenbach, "Left behind by design: Proficiency counts and test-based accountability," Review of Economics and Statistics, 2010, 92 (2), 263-283. 
Nunes, Luis C, Ana Balc ao Reis, and Carmo Seabra, "The publication of school rankings: A step toward increased accountability?," Economics of Education Review, 12 2015, 49, 15-23.

Reback, Randall, Jonah Rockoff, and Heather L Schwartz, "Under pressure: Job security, resource allocation, and productivity in school under No Child Left Behind," American Economic Journal: Economic Policy, August 2014, 6 (3), 207-241.

RISE Tanzania Country Research Team, "Monitoring the Big Results Now in Education program," Georgetown University, Initiative on Innovation, Development, and Evaluation, Technical Report. October 2017.

Rockoff, Jonah and Lesley J Turner, "Short-run impacts of accountability on school quality," American Economic Journal: Economic Policy, November 2010, 2 (4), 119-147.

Rouse, Cecilia Elena, Jane Hannaway, Dan Goldhaber, and David Figlio, "Feeling the Florida heat? How low-performing schools respond to voucher and accountability pressure," American Economic Journal: Economic Policy, May 2013, 5 (2), 251-281.

Tai Hsieh, Chang and Miguel Urquiola, "The effects of generalized school choice on achievement and stratification: Evidence from Chile's voucher program," Journal of Public Economics, 2006, 90, 1477-1503.

Todd, Robin and Ian Attfield, "Big Results Now! in Tanzanian Education: Has the delivery approach delivered?," 2017. Technical Report, Cambridge Education.

Twaweza, "Capitation grant for education: when will it make a difference?," Uwazi policy brief 8, Twaweza, Dar es Salaam 2010.

_, "Are Our Children Learning? Literacy and Numeracy in Tanzania," Uwezo National Report, Uwezo 2012.

_ , "Capitation grants in primary education: A decade since their launch, does money reach schools?," Sauti za Wananchi brief 3, Twaweza, Dar es Salaam June 2013.

Valente, Christine, "Primary education expansion and quality of schooling: Evidence from Tanzania," IZA Discussion Paper, IZA 2015.

World Bank, "Tanzania Education Program for Results," Implementation Status and Results Report P147486 No. 2, World Bank, Washington D.C. 2015.

_ , "Education service delivery in Tanzania," Education Technical Report, Tanzania 2014 Service Delivery Indicators, International Bank for Reconstruction and Development / The World Bank. 2016. 
_ , "Tanzania Education Program for Results," Implementation Status and Results Report P147486 No. 5, World Bank, Washington D.C. 2016.

_ , "Tanzania Education Program for Results," Implementation Status and Results Report P147486 No. 4, World Bank, Washington D.C. 2016.

_ , "Tanzania Education Program for Results," Implementation Status and Results Report P147486 No. 7, World Bank, Washington D.C. 2018.

_ , World Development Report 2018: Learning to realize education's promise, Washington, DC: International Bank for Reconstruction and Development / The World Bank, 2018. 
Figure 1: Exam performance by within-district decile rank-pre vs post reform.

(a) Pre-reform with post-reform (average score)

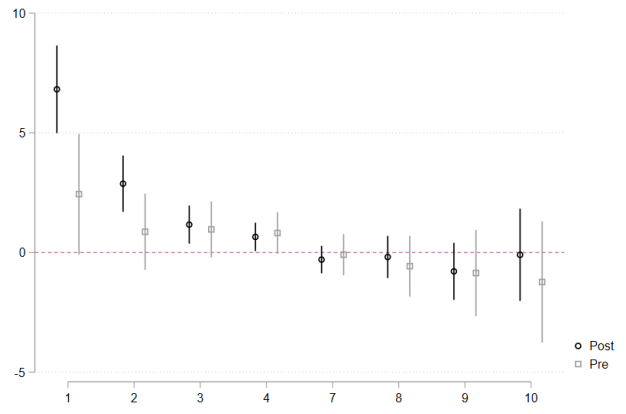

(c) Pre-reform with post-reform (pass rate)

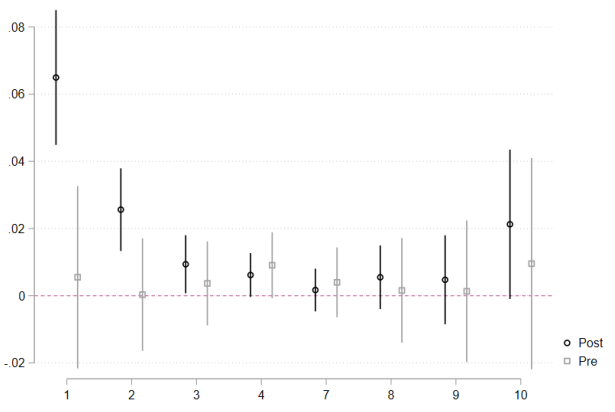

(b) Difference-in-difference estimates (average score)

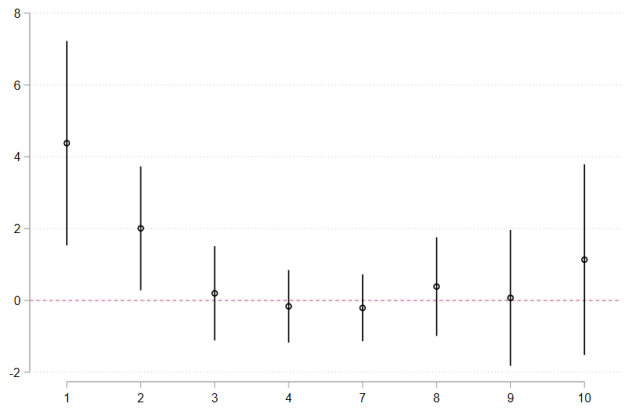

(d) Difference-in-difference estimates (pass rate)

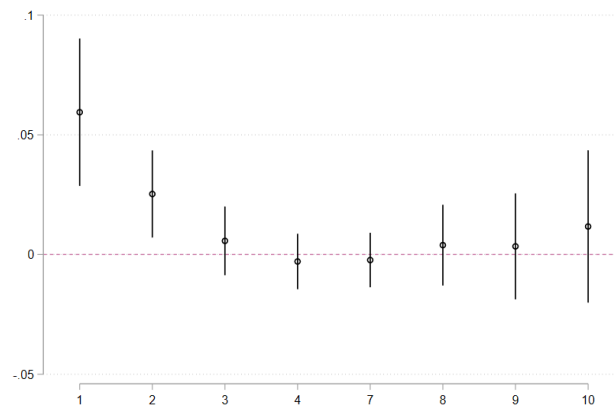

Note: All panels show regression coefficients and 90 percent confidence intervals, estimated using Equation (1). In panels (a) and (c) the light lines refer to the pre-reform period $\left(\hat{\alpha}_{q}\right)$, and the dark lines refer to the post-reform period $\left(\hat{\alpha}_{q}+\hat{\beta}_{q}\right)$. Panels (b) and (d) shows results for the difference in these ranking decile effects between pre- and post periods $\left(\hat{\beta}_{q}\right)$. In both the preand post-reform periods, schools are compared to schools in the middle two deciles of the district rank. In panels (a) and (b) the outcome is a school average exam performance, scaled from zero to 250; in panels (c) and (d) the outcome is pass rate. 
Table 1: Descriptive statistics.

\begin{tabular}{|c|c|c|c|c|c|c|}
\hline & 2011 & 2012 & 2013 & 2014 & 2015 & 2016 \\
\hline \multicolumn{7}{|l|}{ Panel A: NECTA } \\
\hline Average marks & $\begin{array}{l}111.31 \\
(26.76)\end{array}$ & $\begin{array}{c}85.96 \\
(22.28)\end{array}$ & $\begin{array}{l}102.76 \\
(24.51)\end{array}$ & $\begin{array}{l}108.65 \\
(26.14)\end{array}$ & $\begin{array}{l}120.41 \\
(30.17)\end{array}$ & $\begin{array}{l}119.17 \\
(27.60)\end{array}$ \\
\hline Average number of test takers & - & $\begin{array}{c}56.34 \\
(37.82)\end{array}$ & $\begin{array}{c}53.97 \\
(37.92)\end{array}$ & $\begin{array}{c}49.92 \\
(36.44)\end{array}$ & $\begin{array}{c}47.44 \\
(36.08)\end{array}$ & $\begin{array}{c}48.29 \\
(37.49)\end{array}$ \\
\hline Average number of passed candidates & - & $\begin{array}{c}17.31 \\
(22.89)\end{array}$ & $\begin{array}{c}27.31 \\
(28.95)\end{array}$ & $\begin{array}{c}28.45 \\
(28.67)\end{array}$ & $\begin{array}{c}32.18 \\
(30.48)\end{array}$ & $\begin{array}{c}33.97 \\
(31.42)\end{array}$ \\
\hline Average pass rate & - & $\begin{array}{c}0.29 \\
(0.25)\end{array}$ & $\begin{array}{c}0.49 \\
(0.28)\end{array}$ & $\begin{array}{c}0.56 \\
(0.28)\end{array}$ & $\begin{array}{c}0.67 \\
(0.27)\end{array}$ & $\begin{array}{c}0.69 \\
(0.25)\end{array}$ \\
\hline Total number of test takers & $1,010,084$ & 865,534 & 844,921 & 792,118 & 763,602 & 789,236 \\
\hline National pass rate & 0.58 & 0.31 & 0.51 & 0.57 & 0.68 & 0.70 \\
\hline Number of schools & 14,939 & 15,362 & 15,656 & 15,867 & 16,096 & 16,344 \\
\hline Number of districts & 136 & 136 & 151 & 166 & 166 & 184 \\
\hline \multicolumn{7}{|l|}{ Panel B: EMIS data } \\
\hline \multirow[t]{2}{*}{ Private school } & - & - & - & - & .05 & .05 \\
\hline & - & - & - & - & $(0.22)$ & $(0.22)$ \\
\hline Grade 4 enrollment & - & - & - & $\begin{array}{l}- \\
-\end{array}$ & $\begin{array}{c}67.32 \\
(50.76)\end{array}$ & $\begin{array}{c}63.46 \\
(49.45)\end{array}$ \\
\hline \multirow[t]{2}{*}{ Grade 5 enrollment } & - & - & - & - & 63.33 & 61.83 \\
\hline & - & - & - & - & $(47.68)$ & $(46.71)$ \\
\hline \multirow[t]{2}{*}{ Grade 6 enrollment } & - & - & - & - & 61.68 & 61.58 \\
\hline & - & - & - & - & $(47.23)$ & $(45.93)$ \\
\hline \multirow[t]{2}{*}{ Grade 7 enrollment } & - & - & - & - & 49.36 & 48.82 \\
\hline & - & - & - & - & $(38.99)$ & $(38.11)$ \\
\hline Total number of schools & - & - & - & - & 16,178 & 16,351 \\
\hline \multicolumn{7}{|l|}{ Panel C: Service Delivery Indicators } \\
\hline \multirow[t]{2}{*}{ Average classroom presence } & - & - & - & 0.52 & - & 0.59 \\
\hline & - & - & - & $(0.23)$ & - & $(0.22)$ \\
\hline \multirow[t]{2}{*}{ Average number of teachers } & - & - & - & 17.47 & - & 17.48 \\
\hline & - & - & - & $(1.73)$ & - & $(2.39)$ \\
\hline \multirow[t]{2}{*}{ Capitation grants received (TSh/student) } & - & - & 5,134 & - & 5,966 & - \\
\hline & - & - & $(3,891)$ & - & $(17,796)$ & - \\
\hline \multirow[t]{2}{*}{ Textbooks received per student } & - & - & 0.12 & - & 0.63 & - \\
\hline & - & - & $(0.45)$ & - & $(.84)$ & - \\
\hline \multirow[t]{2}{*}{ Number of inspections } & - & - & 1.56 & - & 1.45 & - \\
\hline & - & - & $(2.65)$ & - & $(1.74)$ & - \\
\hline Number of schools & - & - & - & 395 & - & 395 \\
\hline
\end{tabular}

Panel one shows school-average examinations performance, collected by the National Examination Council of Tanzania (NECTA); Panel B reports enrollment data, according to the Education Management Information System (EMIS). School-level EMIS data is only available for 2015 and 2016. Panel C reports the summary data for key variables used from the Service Delivery Indicators (SDI) dataset. The SDI data was collected in 2014 and 2016, but some variables were collected jusing the previous year (2013 or 2015) as the reference period. Means and standard deviations reported, unless otherwise noted. Capitation (or per-pupil) grants are reported in nominal Tanzanian shillings (TSh) 
Table 2: Impacts of the reform on school exam performance

\begin{tabular}{|c|c|c|c|c|c|c|}
\hline & \multicolumn{2}{|c|}{ Marks } & \multicolumn{2}{|c|}{ Pass rate } & \multicolumn{2}{|c|}{ Number passed } \\
\hline & (1) & (2) & (3) & (4) & (5) & $(6)$ \\
\hline 0 -10th percentile in previous year & $\begin{array}{c}4.406^{* * *} \\
(1.004)\end{array}$ & $\begin{array}{l}6.147^{* * *} \\
(0.849)\end{array}$ & $\begin{array}{c}0.058^{* * *} \\
(0.012)\end{array}$ & $\begin{array}{l}0.079^{* * *} \\
(0.011)\end{array}$ & $\begin{array}{l}1.828^{*} \\
(1.026)\end{array}$ & $\begin{array}{l}2.180^{* * *} \\
(0.754)\end{array}$ \\
\hline $10-20$ th percentile in previous year & $\begin{array}{c}2.049^{* * *} \\
(0.563)\end{array}$ & $\begin{array}{l}2.382^{* * *} \\
(0.578)\end{array}$ & $\begin{array}{c}0.024^{* * *} \\
(0.006)\end{array}$ & $\begin{array}{l}0.030^{* * *} \\
(0.007)\end{array}$ & $\begin{array}{c}0.930 \\
(0.845)\end{array}$ & $\begin{array}{l}0.852^{* *} \\
(0.379)\end{array}$ \\
\hline Diff-diff & Yes & Yes & Yes & Yes & Yes & Yes \\
\hline School fixed effects & No & Yes & No & Yes & No & Yes \\
\hline Control lagged exam score & Yes & Yes & Yes & Yes & Yes & Yes \\
\hline Control mean, post BRN & 109.46 & 109.46 & 0.58 & 0.58 & 30.82 & 30.82 \\
\hline Observations & 77731 & 77431 & 77731 & 77431 & 77731 & 77431 \\
\hline R-squared & 0.655 & 0.801 & 0.607 & 0.763 & 0.425 & 0.912 \\
\hline
\end{tabular}

Each column represents a separate regression. All specifications include district-by-year fixed effects, flexible controls for lagged test scores, and indicators pre-reform associations between district-rank deciles and subsequent outcomes. Reported coefficients correspond to the differential effect of being ranked in the associated decile of within-district performance in the post- (vs. pre-)reform period, compared to the middle six deciles. In even columns, the specification is augmented with school fixed effects. In Columns (1) and (2) the outcome is the average PSLE score (ranging from 0-250), in Columns (3) and (4) it is the pass rate, and in the Columns (5) and (6) it is the number of pupils who passed. 300 singleton schools are dropped when results are estimated using school fixed effects. Standard errors are clustered at the district level. 
Table 3: Number of test takers and enrollment

\begin{tabular}{|c|c|c|c|c|c|c|}
\hline & \multicolumn{2}{|c|}{ PSLE data - exam sitters } & \multicolumn{4}{|c|}{ EMIS data- enrollment } \\
\hline & (1) & $(2)$ & $(3)$ & $(4)$ & $(5)$ & $(6)$ \\
\hline & All years & 2015 and 2016 & Grades $4-6$ & Grade 6 & Grade 7 & Grade $7 /$ Grade 6 \\
\hline 0-10th percentile in previous year & $\begin{array}{c}-2.039^{* * *} \\
(0.763)\end{array}$ & $\begin{array}{l}-1.676^{* * *} \\
(0.589)\end{array}$ & $\begin{array}{c}-0.773 \\
(1.787)\end{array}$ & $\begin{array}{l}-0.329 \\
(0.882)\end{array}$ & $\begin{array}{c}-1.646^{* *} \\
(0.737)\end{array}$ & $\begin{array}{l}-0.028^{* *} \\
(0.013)\end{array}$ \\
\hline $10-20$ th percentile in previous year & $\begin{array}{c}-1.846^{* * *} \\
(0.635)\end{array}$ & $\begin{array}{l}-1.068^{* *} \\
(0.423)\end{array}$ & $\begin{array}{l}1.929 \\
(1.334)\end{array}$ & $\begin{array}{l}0.865 \\
(0.659)\end{array}$ & $\begin{array}{l}-0.479 \\
(0.480)\end{array}$ & $\begin{array}{l}-0.008 \\
(0.010)\end{array}$ \\
\hline Diff-diff & Yes & No & No & No & No & No \\
\hline Control lagged exam score & Yes & Yes & Yes & Yes & Yes & Yes \\
\hline Fixed effects & Yes & Yes & Yes & Yes & Yes & Yes \\
\hline Control mean & 52.01 & 50.07 & 197.14 & 64.10 & 51.55 & 0.84 \\
\hline Observations & 77431 & 31520 & 31150 & 31150 & 31150 & 15828 \\
\hline R-squared & 0.910 & 0.953 & 0.968 & 0.930 & 0.931 & 0.127 \\
\hline
\end{tabular}

Each column represents a separate regression. All specifications include flexible controls for lagged test scores and school and district-by-year fixed effects. Column (1) is estimated on outcomes from 2012-2016, including indicators for pre-reform associations between district-rank deciles and subsequent outcomes. Reported coefficients in that column correspond to the differential effect of being ranked in the associated decile of within-district performance in the post- (vs. pre-)reform period, compared to the middle six deciles. In the columns (2) to (6), data is restricted to post-reform years 2015-2016 in which EMIS data are available; this does not allow for a difference-in-difference specification. In columns (1) and (2) the outcome variable is the number students sitting the exam, using PSLE data. In columns (3) to (6), outcomes are different constructions of enrollment, based on EMIS data. The outcome in Columns (3) to (5) is the number of students enrolled in the corresponding grade(s). In Column (6), the outcome indicator is Grade 7 enrollment in 2016 divided by Grade 6 enrollment in 2015. Standard errors are clustered at the district level. 
Table 4: District ranking impacts on monitoring, teacher effort, resource spending and allocation

\begin{tabular}{|c|c|c|c|c|c|}
\hline & $\begin{array}{c}(1) \\
\text { Teachers }\end{array}$ & $\begin{array}{c}(2) \\
\text { Textbook }\end{array}$ & $\begin{array}{c}\text { (3) } \\
\text { Capitation grants }\end{array}$ & $\begin{array}{c}(4) \\
\text { Inspections }\end{array}$ & $\begin{array}{c}(5) \\
\text { Teacher presence }\end{array}$ \\
\hline 0 -10th percentile in previous year & $\begin{array}{c}0.921 \\
(0.665)\end{array}$ & $\begin{array}{c}0.110 \\
(0.174)\end{array}$ & $\begin{array}{c}0.202 \\
(0.976)\end{array}$ & $\begin{array}{l}-0.298 \\
(0.544)\end{array}$ & $\begin{array}{l}-0.036 \\
(0.082)\end{array}$ \\
\hline $10-20$ th percentile in previous year & $\begin{array}{l}-0.202 \\
(0.500)\end{array}$ & $\begin{array}{l}-0.139 \\
(0.084)\end{array}$ & $\begin{array}{l}-1.052 \\
(0.669)\end{array}$ & $\begin{array}{c}0.782 \\
(0.552)\end{array}$ & $\begin{array}{l}-0.015 \\
(0.057)\end{array}$ \\
\hline $\begin{array}{l}\text { Post-BRN mean: 20-80th percentile } \\
\text { Observations }\end{array}$ & $\begin{array}{c}17.88 \\
760\end{array}$ & $\begin{array}{l}0.38 \\
754\end{array}$ & $\begin{array}{l}3857.17 \\
756\end{array}$ & $\begin{array}{l}1.49 \\
758\end{array}$ & $\begin{array}{c}0.54 \\
760\end{array}$ \\
\hline
\end{tabular}

Each column represents a separate regression, estimated using SDI data, with flexible controls for lagged test scores and district-by-year and school fixed effects. Coefficients correspond to the effect of being ranked in the associated decile of within-district performance in the post-reform period, compared to the middle six deciles. The SDI data was collected in 2014 and 2016 (the post-reform period), but some variables were collected using the previous year (2013 or 2015) as the reference period. For each column, only two years of data are available: columns (1), (4) and (5) use outcomes for the years of 2014 and 2016, and columns (2) and (3) use outcomes for the years 2013 and 2015. The dependent variables in columns (2) and (3) are inverse hyperbolic sine transformations (an approximation for the natural logarithm) and calculated at a per-student level, using enrollment data from 2014. Data from Column (3) is reported in Tanzanian shillings. The mean values reported in the penultimate row is of the un-transformed outcome. We adjust for outliers in the following way: (i) we adjust downwards the per student capitation grant to the maximum that a school can receive, 10,000 Tanzanian shillings; and (ii) we set as missing one school that reported to receive 600 textbooks per student. Since the specifications include school fixed effects, schools with only one observation are dropped. Standard errors are clustered at the district level. 


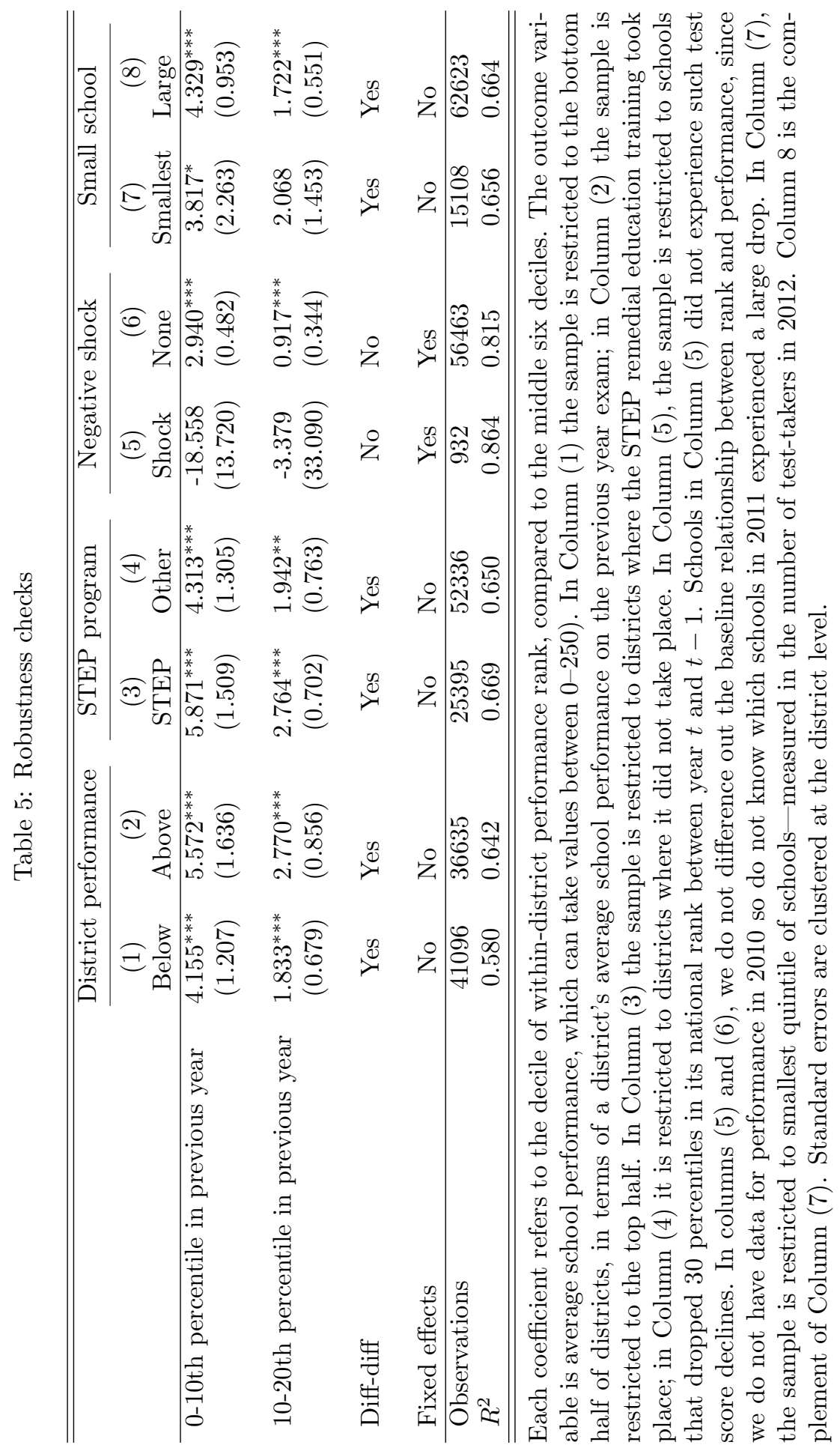




\section{Appendix A Supplementary figures}

Figure A.1: Absolute PSLE scores and within-district ranks, all years

$[2011]$

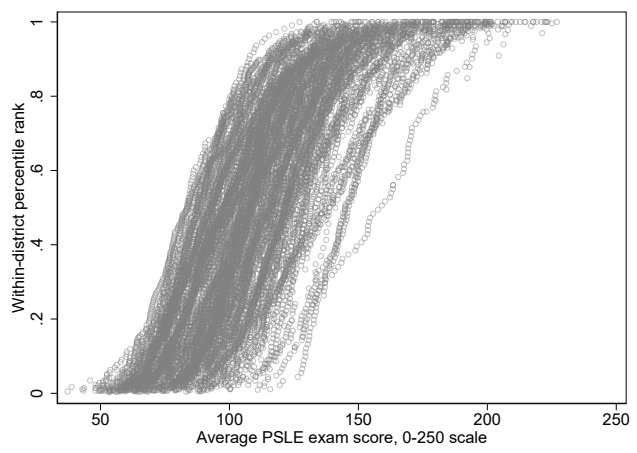

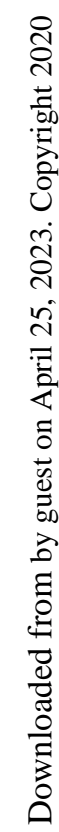

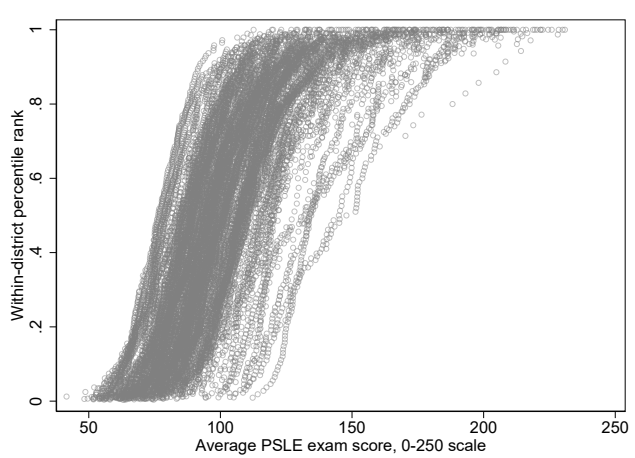

[2013]

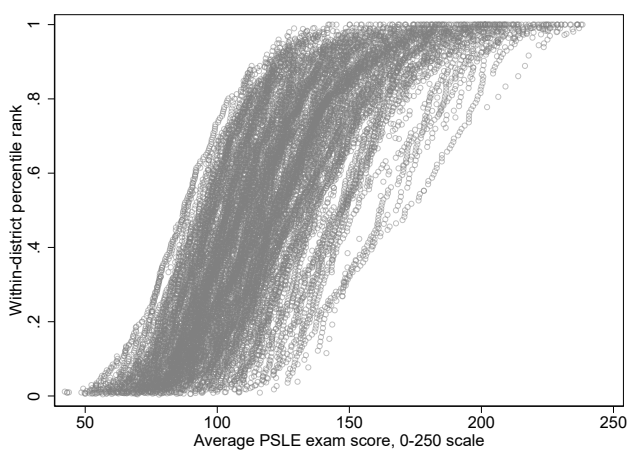

[2012]
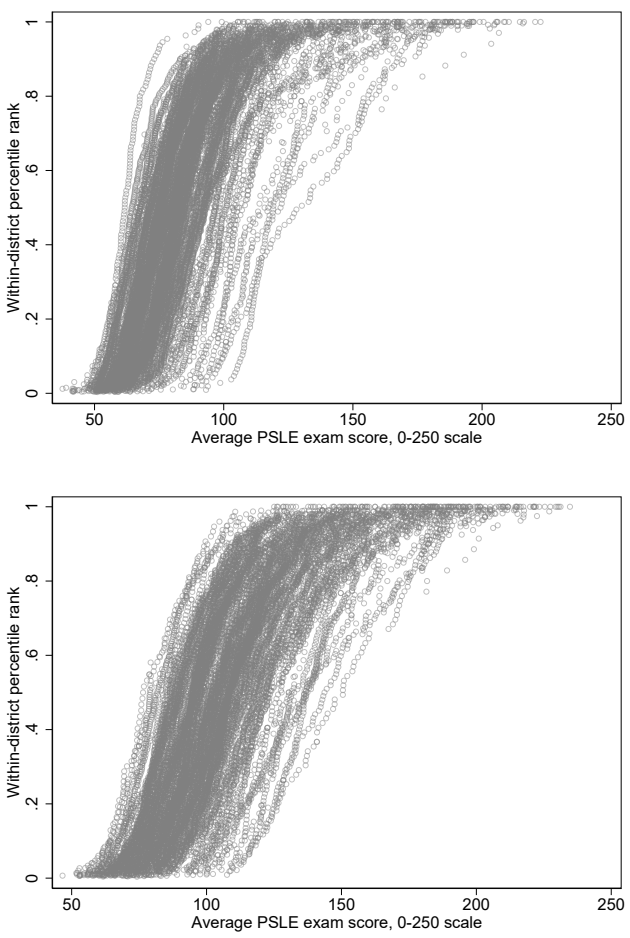

[2014]

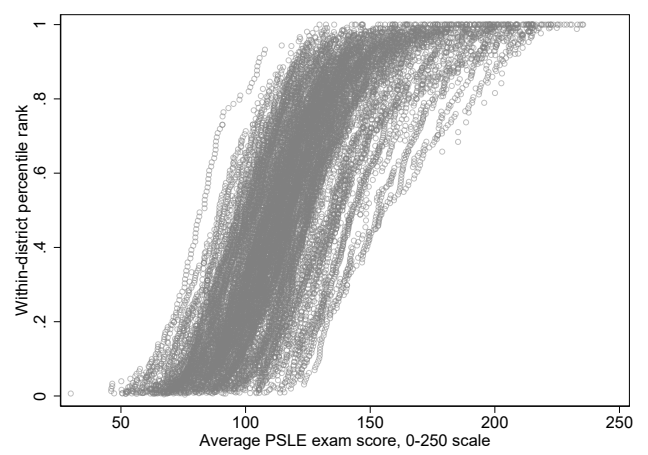

[2015] $[2016]$

Note: Figures illustrates relationship between the average PSLE score of students in a school and the school's rank in its district in the corresponding year. 
Appendix B Supplmentary tables 
Table B.1: Big Results Now in Education Initiatives

\begin{tabular}{cl}
\hline \multirow{3}{*}{ Official school ranking } & \multicolumn{1}{c}{ I. Pressure to perform } \\
& Ranks all government primary (and secondary schools) by \\
& pass rates in PSLE (and CSEE). Each exam has 10 \\
& performance bands, which are classified as green, yellow, \\
& or red. Results publicly posted and widely disseminated. \\
& Both national rankings and district rankings were \\
& distributed.
\end{tabular}

School incentive scheme

Teacher motivation

National 3R

Assessment

3R Teacher Training

Student Teacher

Enrichment

Programme (STEP)

School improvement toolkit

Capitation grants

\section{Teacher motivation}

Providing both non-monetary incentives (certificates) to high performing teachers, as well as clearing all outstanding payment arrears for teachers.

\section{Back to basics}

Early learning assessments (Grade 2) under the 3R (reading, writing, and arithmetic) assessment program on a set of randomly selected schools.

Teacher training program for Grade 1 and 2 teachers on how to teach reading, writing and arithmetic most effectively to this age group. Through a cascade model $37.5 \%$ of schools in 40 low-performing districts (out of 136) will be trained.

STEP trained primary and secondary school teachers on how to identify and support low performing students. Teachers were trained on how to conduct diagnostic tests to determine which students need extra coaching, as well as how to develop curriculum and conduct classes for low performing students.

\section{$I V$. School management and finance}

The programs aims to train head-teachers of primary and secondary schools on best practices in the management of schools. A practical toolkit of these practices was distributed to head-teachers.

Timely disbursement of sufficient capitation grants for
Annual monetary and non-monetary incentives for primary and secondary schools that have most improved their performance in the national exams (PSLE \& CSEE).
Fully implemented through 2016.

Partially implemented: 60 primary schools received financial awards in 2015. Almost 4000 non-monetary awards (certificates) distributed to primary and secondary schools starting in 2016 . No awards prior to 2015. primary and secondary schools; as well as equalization of funding per student per district (about USD 4.6 per primary student and USD 11.6 per secondary student).
Partially implemented: outstanding claims reduced by a third by 2016 .

Implemented: assessment conducted in 2016.

Implemented: Almost 60,000 teachers were trained by 2016 . Training started in 2014.

Partially implemented: teachers from 5500 primary schools were trained. Training started in 2014.

Implemented: More than 16,000 primary schools received the materials. Distribution started in 2014.

Late implementation: prior to $2016,31 \%$ of schools received funds on time. In 2016 about $90 \%$ of schools received funds on time.

Notes: The delays in implementation were due to lack of funding. BRN was not adequately funded until donors provided funding in 2015. The information displayed in this table is compiled from a series of World Bank Project Implementation Status Reports and Tanzania Government reports (Government of Tanzania, 2015; World Bank, 2015, 2016b,c). 
Table B.2: Pre-BRN outcome levels

\begin{tabular}{lcccc}
\hline & Number Passed & Average Marks & Exam sitters & Pass rate (\%) \\
\hline 0-10th Percentile in 2012 & 8.4 & 72.8 & 47.6 & 15.5 \\
& $(15.3)$ & $(15.1)$ & $(34.2)$ & $(17.0)$ \\
10-20th Percentile in 2012 & 11.0 & 75.6 & 54.1 & 17.9 \\
& $(16.9)$ & $(14.2)$ & $(36.7)$ & $(16.5)$ \\
\hline
\end{tabular}

Notes: Table presents means and standard deviations of key outcomes in 2012. Calculated from NECTA data. 
Table B.3: Impacts on the probability of a school being in the bottom decile or quintile in its district

\begin{tabular}{lcccccc}
\hline \hline & \multicolumn{2}{c}{ Bottom decile } & & \multicolumn{2}{c}{ Bottom quintile } \\
\cline { 2 - 3 } \cline { 6 - 6 } & $(1)$ & $(2)$ & & $(3)$ & $(4)$ \\
\hline 0-10th percentile in previous year & $-0.056^{* * *}$ & $-0.309^{* * *}$ & & $-0.085^{* * *}$ & $-0.362^{* * *}$ \\
& $(0.021)$ & $(0.018)$ & & $(0.025)$ & $(0.021)$ \\
10-20th percentile in previous year & -0.007 & 0.006 & & -0.030 & $-0.275^{* * *}$ \\
& $(0.013)$ & $(0.013)$ & & $(0.018)$ & $(0.016)$ \\
Diff-diff & Yes & Yes & & Yes & Yes \\
School fixed effects & No & Yes & & No & Yes \\
& & & & \\
Control lagged exam score & Yes & Yes & & Yes & Yes \\
\hline Observations & 77731 & 77431 & & 77731 & 77431 \\
R-squared & 0.089 & 0.391 & & 0.126 & 0.428 \\
\hline \hline
\end{tabular}

Notes: Each column represents a separate regression. All specifications include district-by-year fixed effects, flexible controls for lagged test scores, and indicators pre-reform associations between district-rank deciles and subsequent outcomes. Reported coefficients correspond to the differential effect of being ranked in the associated decile of within-district performance in the post- (vs. pre-)reform period, compared to the middle six deciles. Columns (2) and (4) include school fixed effects. The outcome in columns (1) and (2) is an indicator for whether the school is in the bottom decile of its district rank; the outcome in columns (3) and (4) is an indicator for whether the school is in the bottom quintile of its district rank. Standard errors are clustered at the district level. 
Table B.4: Testing for sorting

\begin{tabular}{|c|c|}
\hline & $\begin{array}{c}(1) \\
\text { Exam sitters }\end{array}$ \\
\hline 0 -10th percentile in previous year & $\begin{array}{c}-1.771^{* *} \\
(0.759)\end{array}$ \\
\hline 10-20th percentile in previous year & $\begin{array}{c}-2.126^{* * *} \\
(0.622)\end{array}$ \\
\hline 80-90th percentile in previous year & $\begin{array}{l}1.318^{*} \\
(0.681)\end{array}$ \\
\hline 90-100th percentile in previous year & $\begin{array}{c}1.451 \\
(0.895)\end{array}$ \\
\hline Ward: 0-10th pctile in previous year & $\begin{array}{l}-1.081 \\
(1.075)\end{array}$ \\
\hline Ward: $10-20$ th pctile in previous year & $\begin{array}{c}1.242 \\
(1.315)\end{array}$ \\
\hline Ward: $80-90$ th pctile in previous year & $\begin{array}{l}-1.553 \\
(1.288)\end{array}$ \\
\hline Ward: $90-100$ th pctile in previous year & $\begin{array}{c}1.011 \\
(1.159) \\
\end{array}$ \\
\hline Observations & 77431 \\
\hline$R^{2}$ & 0.910 \\
\hline
\end{tabular}

Each column represents a separate regression. All specifications include district-by-year fixed effects, flexible controls for lagged test scores, and indicators pre-reform associations between district-rank deciles and subsequent outcomes. The first four coefficients correspond to the differential effect of being ranked in the associated decile of within-district performance in the post (vs. pre-)reform period, compared to the middle six deciles. Coefficients marked 'Ward' correspond to the effect of the share of schools in the ward within a given decile, compared to the middle six deciles, in the post (vs. pre-) reform period. Standard errors are clustered at the district level. 
Table B.5: Impacts of the reform on school exam performance (sample of SDI schools)

\begin{tabular}{lclc}
\hline \hline & $(1)$ & $(2)$ & $(3)$ \\
& Marks & Pass rate & Number passed \\
\hline 0-10th percentile in previous year & $10.00^{* *}$ & $0.130^{* * *}$ & $4.413^{* *}$ \\
& $(4.49)$ & $(0.04)$ & $(1.82)$ \\
10-20th percentile in previous year & -2.913 & -0.0104 & 0.267 \\
& $(3.92)$ & $(0.04)$ & $(1.55)$ \\
\hline Control mean, post BRN & 114.32 & 0.64 & 56.25 \\
Observations & 1534 & 1534 & 1534 \\
R-squared & 0.819 & 0.830 & 0.953 \\
\hline \hline
\end{tabular}

Each column represents a separate regression, estimated with flexible controls for lagged test scores and district-by-year and school fixed effects. Coefficients correspond to the effect of being ranked in the corresponding decile of withindistrict performance in the post-reform period, compared to the middle six deciles. The sample is schools in the SDI sample, for the years 2013 to 2016. Standard errors are clustered at the district level. 
Table B.6: Impacts on student learning outcomes using SDI survey data

\begin{tabular}{lccc}
\hline \hline & $(1)$ & $(2)$ & $(3)$ \\
& Math & English & kiSwahili \\
\hline 0-10th percentile in previous year & -0.027 & 0.377 & -0.382 \\
& $(0.279)$ & $(0.292)$ & $(0.712)$ \\
& & & \\
10-20th percentile in previous year & 0.034 & 0.430 & 0.281 \\
& $(0.195)$ & $(0.310)$ & $(0.453)$ \\
\hline Post-BRN mean: 0-80th percentile & 0.02 & 0.02 & 0.00 \\
Observations & 760 & 760 & 760 \\
\hline \hline
\end{tabular}

Each column represents a separate regression, estimated with flexible controls for lagged test scores and district-by-year and school fixed effects. Coefficients correspond to the effect of being ranked in the corresponding decile of within-district performance in the post-reform period, compared to the middle six deciles. Student learning outcomes are calculated as the first principal component of exam responses and standardized to have mean zero and variance one. The sample is schools in the SDI sample, for the years 2013 and 2016. Standard errors are clustered at the district level. 
Table B.7: Within-district ranking impacts on enrollment, by gender

\begin{tabular}{lccccc}
\hline \hline & \multicolumn{2}{c}{ Grades $4-6$} & & \multicolumn{2}{c}{ Grade 7} \\
\cline { 2 - 3 } & $(1)$ & $(2)$ & & $(3)$ & $(4)$ \\
& Male & Female & & Male & Female \\
\hline 0-10th percentile in previous year & -0.753 & -0.020 & & $-0.805^{*}$ & $-0.841^{*}$ \\
& $(1.130)$ & $(0.829)$ & & $(0.411)$ & $(0.430)$ \\
10-20th percentile in previous year & 1.056 & 0.873 & & -0.304 & -0.175 \\
& $(0.726)$ & $(0.688)$ & & $(0.277)$ & $(0.296)$ \\
\hline Control mean & 95.20 & 101.93 & & 24.14 & 27.41 \\
Observations & 31150 & 31150 & & 31150 & 31150 \\
R-squared & 0.960 & 0.967 & & 0.910 & 0.912 \\
\hline \hline
\end{tabular}

Table replicates results of Table 3, disaggregating enrollment outcomes by gender. Data are EMIS data, available for 2015-2016. Each column represents a separate regression, estimated with flexible controls for lagged test scores and district-by-year and school fixed effects. Coefficients correspond to the effect of being ranked in the corresponding decile of within-district performance in the post-reform period, compared to the middle six deciles. In columns (1) and (2), the outcome is total enrollment in grades 4-6, and in columns (3) and (4) the outcome is enrollment in grade 7. Standard errors are clustered at the district level. 


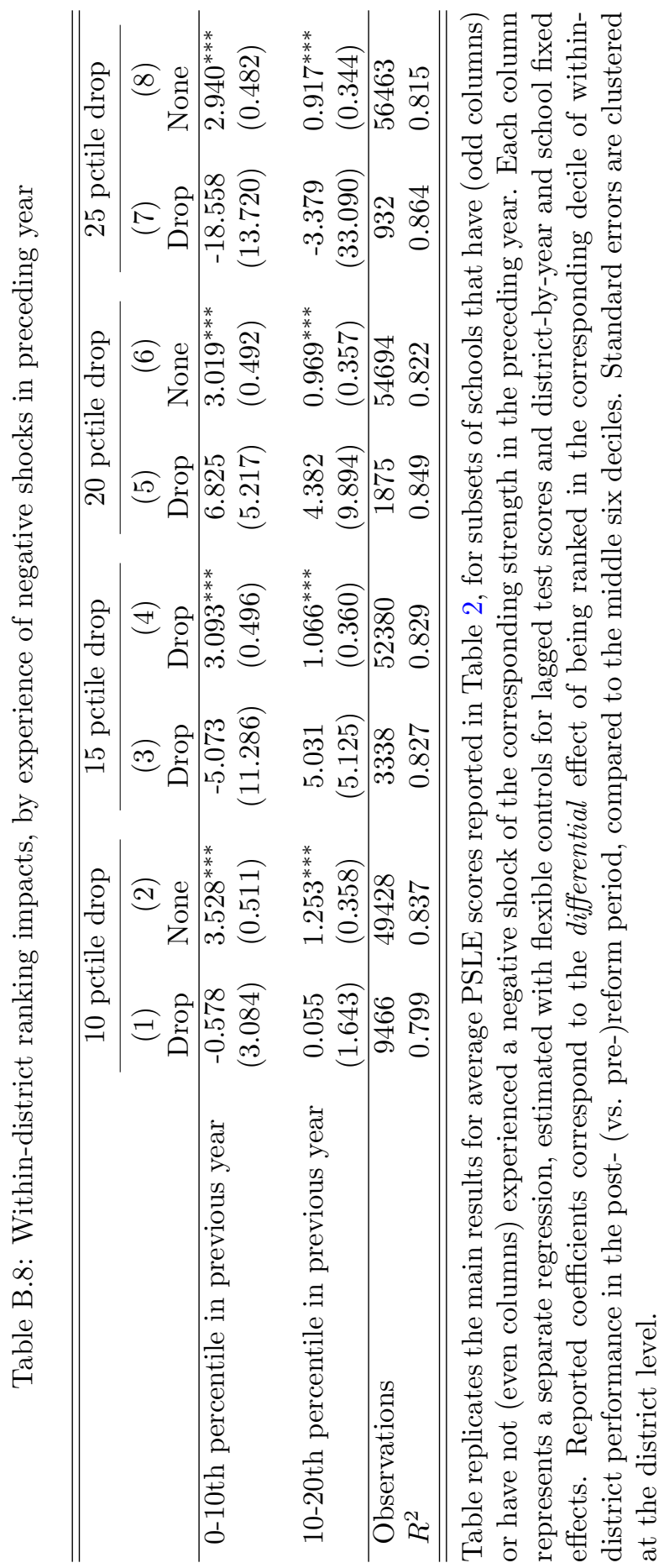


Table B.9: Single difference estimates on PSLE performance, by school size

\begin{tabular}{lcccccccc}
\hline \hline & \multicolumn{3}{c}{ Average score } & & \multicolumn{3}{c}{ Pass rate } \\
\cline { 2 - 3 } & $(1)$ & $(2)$ & $(3)$ & & $(4)$ & $(5)$ & $(6)$ \\
& All schools & Smallest & Large & & All schools & Smallest & Large \\
\hline 0-10th percentile in previous year & $5.648^{* * *}$ & $5.522^{* * *}$ & $5.734^{* * *}$ & & $0.058^{* * *}$ & & $0.047^{* * *}$ & $0.061^{* * *}$ \\
& $(0.682)$ & $(1.249)$ & $(0.739)$ & & $(0.008)$ & & $(0.015)$ & $(0.009)$ \\
& & & & & & \\
10-20th percentile in previous year & $2.025^{* * *}$ & $1.840^{* *}$ & $2.088^{* * *}$ & $0.020^{* * *}$ & & 0.012 & $0.021^{* * *}$ \\
& $(0.414)$ & $(0.891)$ & $(0.452)$ & & $(0.004)$ & & $(0.010)$ & $(0.005)$ \\
\hline Observations & 62792 & 12181 & 50611 & 62792 & & 12181 & 50611 \\
$R^{2}$ & 0.601 & 0.619 & 0.605 & & 0.528 & & 0.506 & 0.545 \\
\hline \hline
\end{tabular}

Each column represents a separate regression, estimated using data from post-reform years only. All specifications include flexible controls for lagged test scores and district-by-year fixed effects. Reported coefficients refer to the effect of being ranked in the associated decile of within-district performance, compared to the middle six deciles. In Columns (1)-(3) the outcome is the average PSLE score (ranging from 0-250); in Columns (4)-(6) it is the pass rate. Columns (2) and (5) use only schools in the bottom quintile of the school size distribution (based on number of testtakers in 2012); columns (3) and (6) use the complementary set of large schools. Standard errors are clustered at the district level. 